\title{
Numerical Modelling Approaches for Assessing Improvements to the Flow Circulation in a Small Lake
}

\author{
Cheng He and Quintin Rochfort \\ National Water Research Institute, Environment Canada, 867 Lakeshore Road, Burlington, ON, Canada L7R 4A6 \\ Correspondence should be addressed to Cheng He, cheng.he@ec.gc.ca
}

Received 9 March 2011; Accepted 21 April 2011

Academic Editor: Agostino Bruzzone

Copyright ( $) 2011$ C. He and Q. Rochfort. This is an open access article distributed under the Creative Commons Attribution License, which permits unrestricted use, distribution, and reproduction in any medium, provided the original work is properly cited.

\begin{abstract}
Kamaniskeg Lake is a long, narrow, and deep small lake located in the northern part of Ontario, Canada. The goals of this paper were to examine various options to improve the water quality in the northern part of the lake by altering the local hydraulic flow conditions. Towards this end, a preliminary screening suggested that the flow circulation could be increased around a central island (Mask Island) in the northern part of the lake by opening up an existing causeway connecting the mainland and central island. Three-dimensional (3D) hydraulic and transport models were adopted in this paper to investigate the hydraulic conditions under various wind forces and causeway structures. The modelling results show that opening the causeway in a few places is unlikely to generate a large flow circulation around the central island. Full circulation only appears to be possible if the causeway is fully removed and a strong wind blows in a favourable direction. The possible reasons for existing water quality variations at the intake of a local WTP (water treatment plant) are also explored in the paper.
\end{abstract}

\section{Introduction}

Kamaniskeg Lake is located in the northern part of Ontario in the Madawaska Valley, and its main axis runs approximately along the north-south. It is a long and narrowshaped lake with two large basins at each end of the lake as shown in Figure 1. The water depth can be greater than $40 \mathrm{~m}$ and the surface area is approximately $23.5 \mathrm{~km}^{2}$. Many cottages are built around the lake, and in summer the lake is much busier than other seasons because of the cottagers and various water-related recreational activities.

As shown in Figure 1, a small residential island (Mask Island), connected to the mainland by a causeway, occupies a large portion of the north basin. A small community with a population of approximately 1300 people is located at the northern end of the shore. The drinking water is taken from the western side of the island and the wastewater is discharged into the lake from the eastern side of the island. The locations of the WTP intake and STP (sewage treatment plant) discharge are displayed in Figure 1. Because of the causeway, the flow is restricted from free circulation around the island, which may potentially affect the water quality in the summer season at the WTP intake of the local community. Elevated colour and turbidity levels have been reported in the region of the WTP intake. The focus of this study is on the investigation of possible options based on the numerical modeling results to improve flow conditions and water quality around Mask Island by partially openingup the existing causeway structures to stimulate more flow activities. The model results would provide quantitative spatial and temporal flow and water quality information to help the local community understand the lake circulation under various possible wind conditions and decide the best possible means of improvement of the water quality in the region being studied. In order to accomplish the above goals, 3-dimensional hydrodynamic and transport models were adopted. The data used to drive and verify the model were collected from the field sites shown in Figure 1.

Numerical hydraulic models have been widely applied in many studies of flow conditions in various sizes of open water bodies [1-6]. The success of the numerical modeling study depends on many factors, such as the adopted model, implementation of the modelling, complexity of the geometry of the studied region, degree of accuracy and 


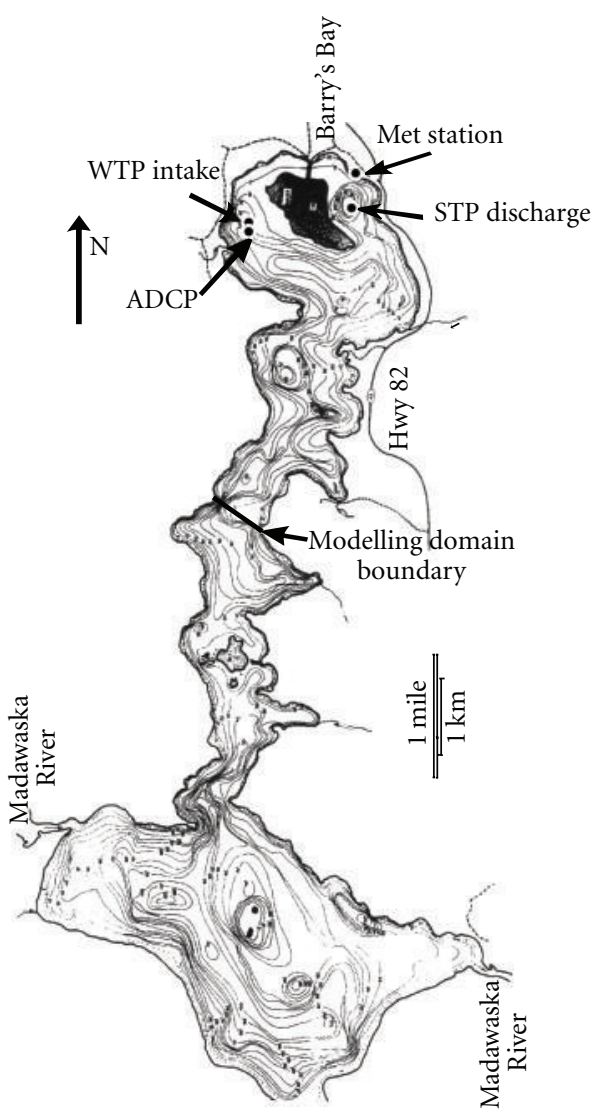

Figure 1: Kamaniskeg Lake map, study region (above the black line area) and locations of the deployed instruments, intake, and discharge.

representation of the measured driving forces, quality of the model, mesh and other well-documented factors, some of which can be improved by careful preparations. However, due to the limitation of the numerical model and the complexity of the natural system, the hydraulic model would be more applicable in some cases than in others. For instance, hydraulic models, in general, perform better to reproduce the flows driven by tides than those induced by wind, and also, they can simulate flow circulation in the coastal zone of a large lake more accurately than in the far field because the flow conditions in the offshore would be much more complex and affected by more complex lake-wide circulation patterns such as internal flow movements. The hydraulic modeling of wind-induced flow circulation in a small lake or reservoir faces more challenges than the similar studies in large lakes because in a small lake, the flow has to change direction more often due to limited space. This results in the flow conditions at one location being more likely affected by flow conditions from other locations and generates complex flow movement modes in most parts of the domain (even in the coastal zone).

\section{Field Data}

In order to provide realistic driving forces for the model simulation, meteorological data was collected in the study area. Wind speed and direction, air temperature, relative humidity, and long- and short-wave solar radiation were collected by NWRI (National Water Research Institute) using a portable data recording meteorological station located in the local sewage treatment plant compound on the edge of the lake; the measurement location is shown in Figure 1. Data was collected for a period of approximately one month from Julian day 224 (August 12) to 259 (September 16, 2009). The wind sensors were about $3 \mathrm{~m}$ above the water surface and measured winds were converted to wind speed at $10 \mathrm{~m}$ above water surface. These converted values, shown in Figure 2, were used as model input for calculation of the wind driving force.

In general, winds were relatively quiet during the measured period as indicated in Figure 2, there were no strong wind events recorded and the maximum recorded wind speed was less than $10 \mathrm{~m} / \mathrm{s}$. Positive $x$ and $y$ components represent wind speed from the west and south, respectively. The four recorded small episodes (as suggested by $y$ wind component in Figure 2) all came from the north-western direction, which is consistent with the local prevailing-wind direction. The stronger $y$ wind component may also be due to the orientation of the lake. The frequency spectra of the wind components, displayed in the bottom panels of Figure 2, indicate that the wind alters directions in the east and west more often than those in the south and north as the high-frequency components in the $y$ direction are much less compared to the high-frequency components in the $x$ direction. The possible reason is that even in summer months, a majority of the local winds still come from either the north east or north west. The period of most of the $y$ wind components winds is around 4 days, and in the $x$ direction, wind periods vary in the range from 1 day to 4 days.

In this study, a well-established, verified, and widely used commercial modeling software package MIKE 3 was adopted, due its ability to handle the complexity and variability of flow movements, especially when induced by wind in a small closed basin with a complex shape. It is always very important to verify the model with available measurements to check and understand the model's suitability for each application and to adjust parameters of the model. To accomplish this, an ADCP (acoustic Doppler current profilers) was deployed to measure flow velocity vertical profile. ADCP measurement location is displayed in Figure 1; it was located near the WTP drinking water intake and mounted on the bottom of the lake facing upwards, between August 12-September 16, 2009. The main purpose for collecting hydraulic data in this study was to verify the model, instead of providing the information for hydraulic study. The ADCP used was a $600 \mathrm{KHZ}$ narrow-band ADCP moored at $15 \mathrm{~m}$ below the water surface with 1 -meter vertical measurement resolution and a 15 -minute sampling rate. The measurement started at $1.8 \mathrm{~m}$ below the surface. The water temperatures were measured at the head of the ADCP and other instruments in the same region (for different studies) for the purpose of specifying model temperature initial condition. 


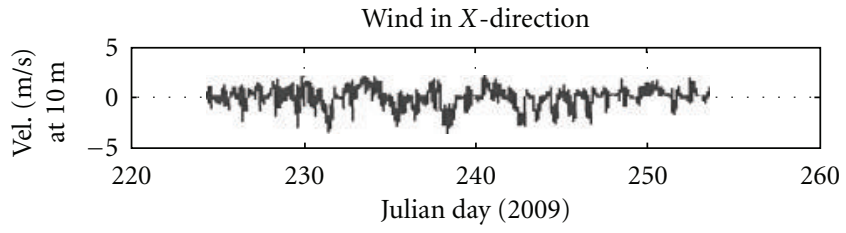

(a)

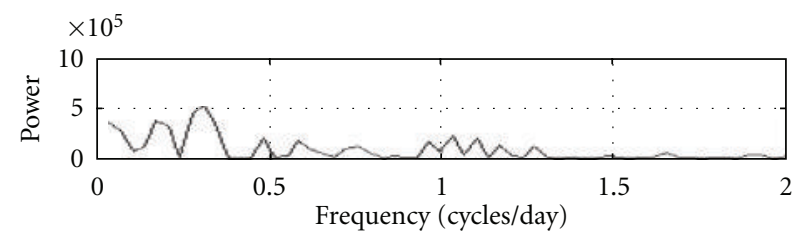

(c)

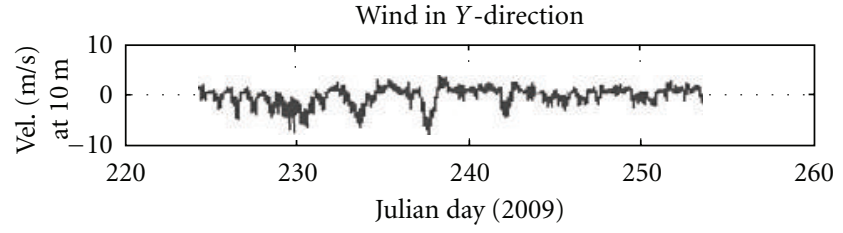

(b)

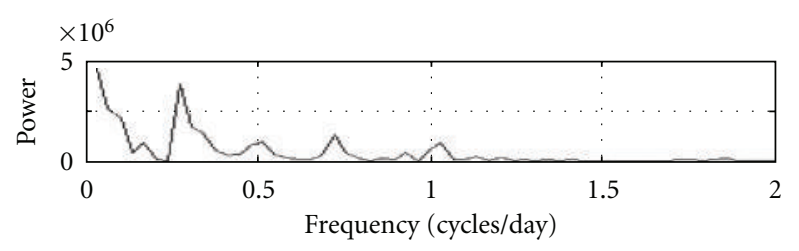

(d)

Figure 2: The top panels are measured local wind components from an onshore 3-meter high portable station, and lower panels are frequency spectra of the wind components.

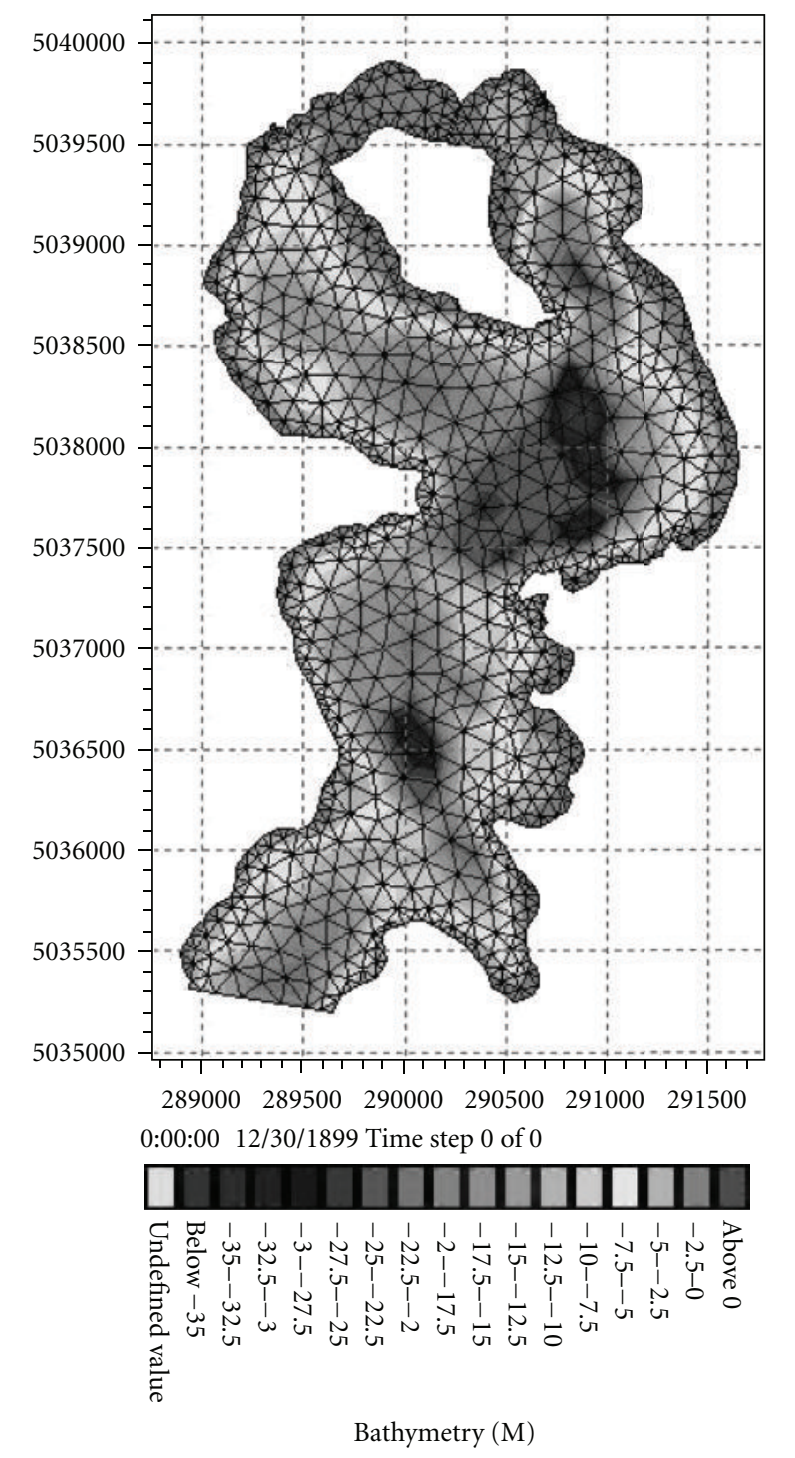

FIGURE 3: The numerical modeling mesh and depth map contours.

\section{Modeling Considerations}

Adapting a suitable numerical model is critical for the success of this study. It can be seen in Figure 3 that the shape of the shoreline in the study region is quite complex and at many locations, changes of depth are very rapid (as indicated by the colour map contour). For a small-sized lake, it is expected that the flow pattern is mainly controlled by wind force. In general, wind-induced flow patterns are characterized by consisting of a series of small circulations. Regardless of the rotational direction and pattern of such circulation, wind usually generates strong coastal currents, which can be better reproduced by a numerical model with a smooth shoreline. This would limit the capacity of models which are based on structured mesh because they are unable to accurately represent the geometry of the coastal zone and would poorly reproduce boundary flow conditions with the staggered shoreline fitting. Therefore, in this study a wellestablished 3D hydrodynamic model, "MIKE 3," developed by the Danish Hydraulic Institute was adopted. It is a finite volume-based model with hydrostatic approximation, using an unstructured and flexible mesh, adapting the $\sigma$ coordinate system for vertical coordinates.

MIKE 3 simulates unsteady three-dimensional flows, taking into account density variation, bathymetry, and external forces arising from meteorology, water elevations, currents, and other hydrographical conditions. The mathematical foundation in MIKE 3 is the mass conservation equation, the Reynolds-averaged Navier-Stokes equations in three dimensions, including the effects of turbulence and variable density, together with the conservation equations for salinity and temperature.

\section{Model Setup and Verifications}

Because this study focuses only on the hydraulic conditions around Mask Island (north part of the lake), considering the size of Kamaniskeg Lake and computer hardware limitations, 


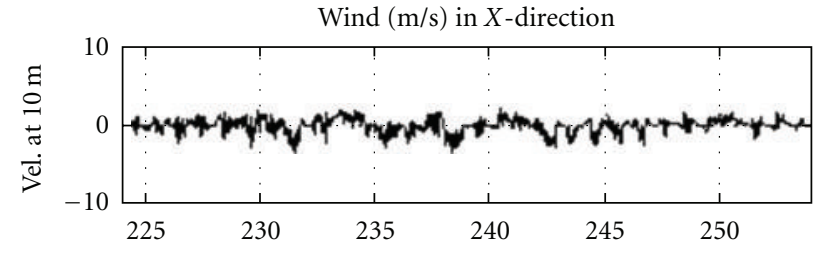

(a)

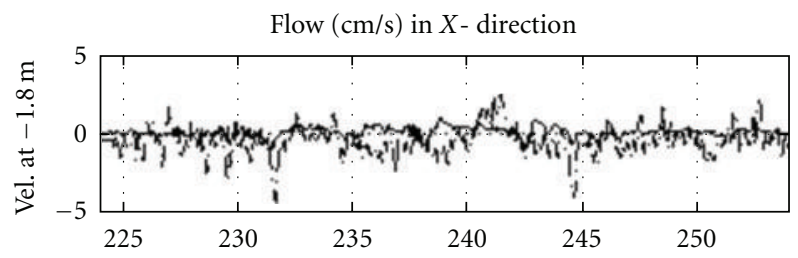

(c)

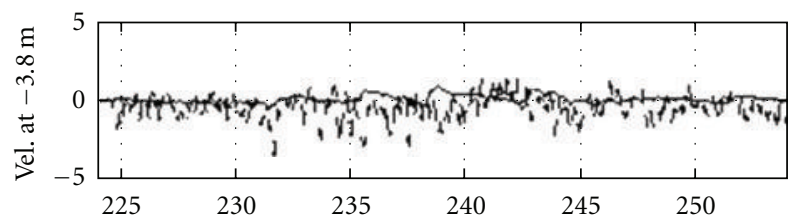

(e)

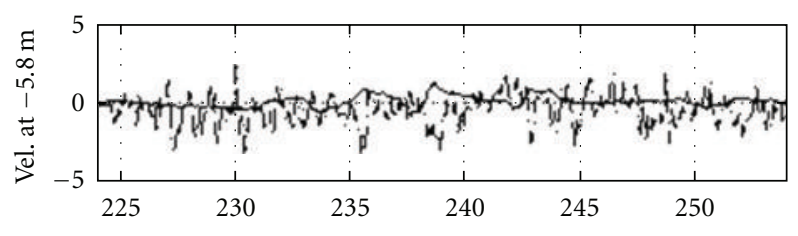

(g)

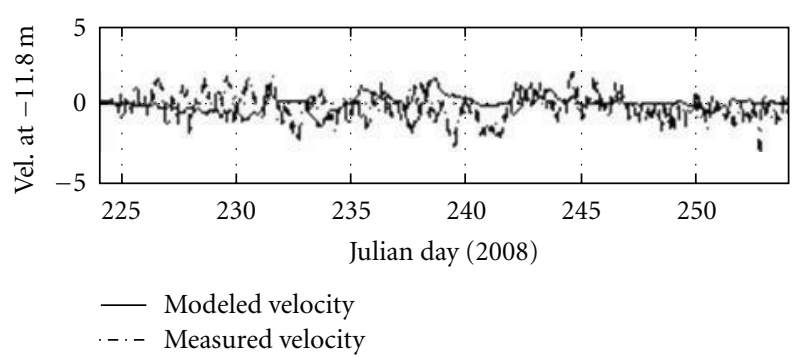

(i)

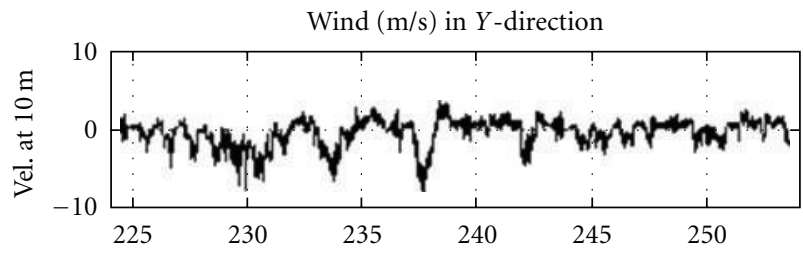

(b)

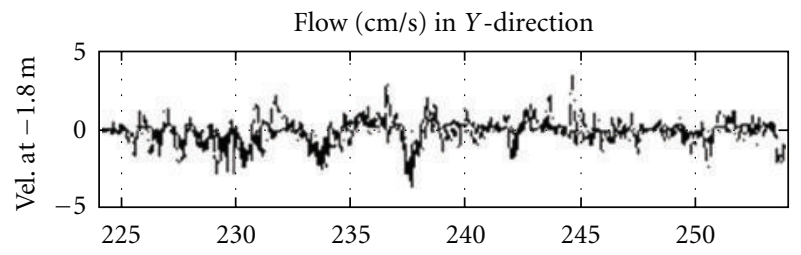

(d)

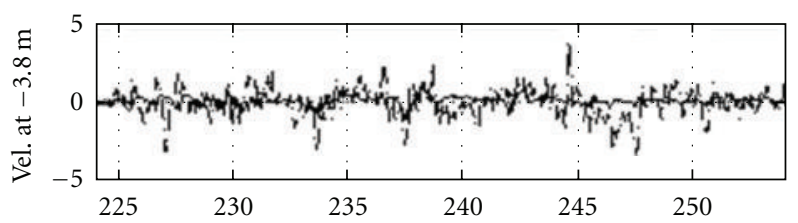

(f)

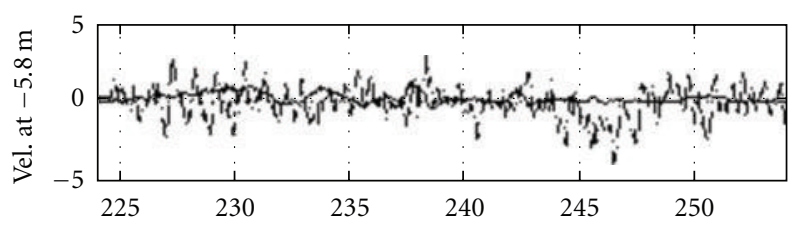

(h)

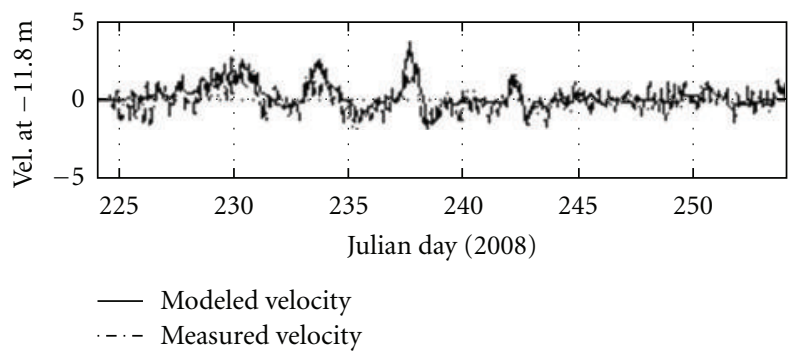

(j)

FIgURE 4: Comparison of the modeled and measured flow velocities at different water depths.

it may not be necessary or efficient to study flow conditions and substance transport in a limited region of interest by including the entire lake. The actual numerical study area is in the region above the black line as indicated in Figure 1 and the modelling mesh used in this study, as displayed in Figure 3, was generated based on the bathymetry data provided by the Canadian Hydrographical Survey. It consists of 1052 nodal points and 1658 triangular elements. A total of 10 vertical layers were chosen in most simulations, which results in a $1: 72$ ratio of computer running time to simulated realtime. It can be seen that because of the unstructured mesh, the complex shoreline is very well represented, which, in turn, should provide more accurate modeling results compared to results from models using a structured mesh. A
30 day simulation was carried out for the purpose of model verification from Julian day 224 (August 12, 2009) to Julian day 259 (September 19, 2009). During this period, there were other water quality-related field studies conducted in the same area of the lake.

In all simulations the first order algorithm was applied to reduce computing time. In MIKE 3 the time step size is automatically adjusted to satisfy the condition of the Courant number $<1$ after minimum and maximum time step sizes are provided; $0.05 \mathrm{~s}$ and $1 \mathrm{~s}$ were used, respectively, for minimum and maximum time step sizes in all simulations. Evenly distributed vertical layers are specified. The Coriolis force has been included in the simulations. The heat exchange through the surface was applied to account for the influence 


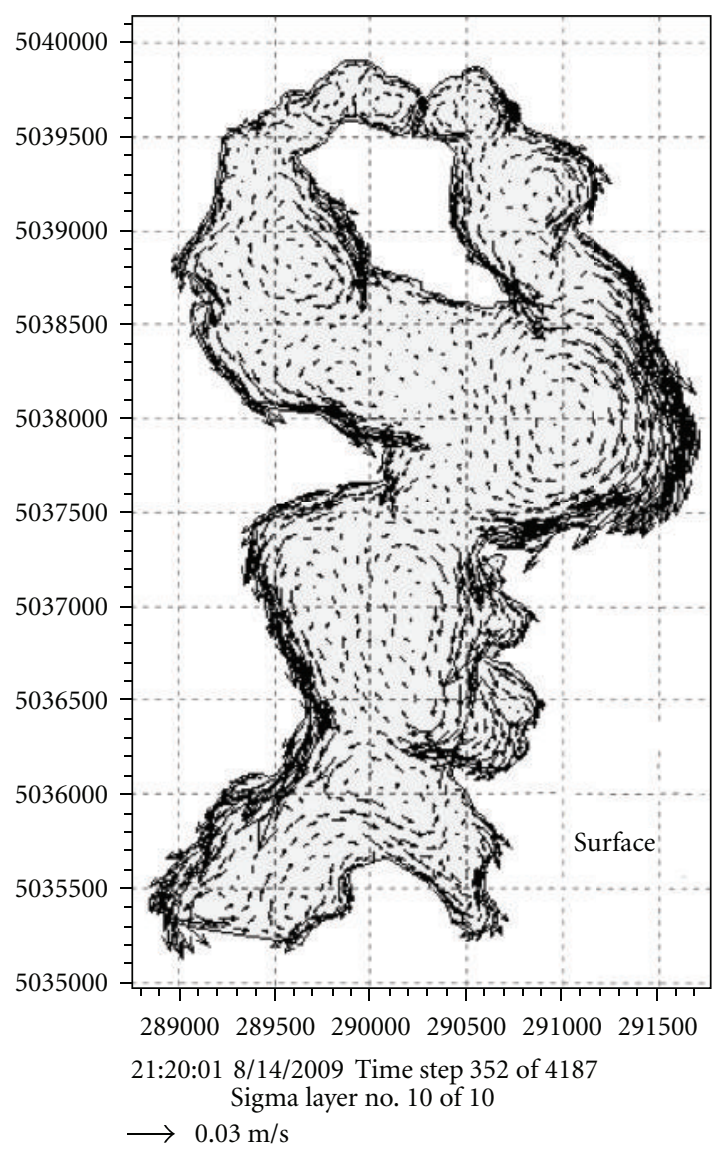

(a)

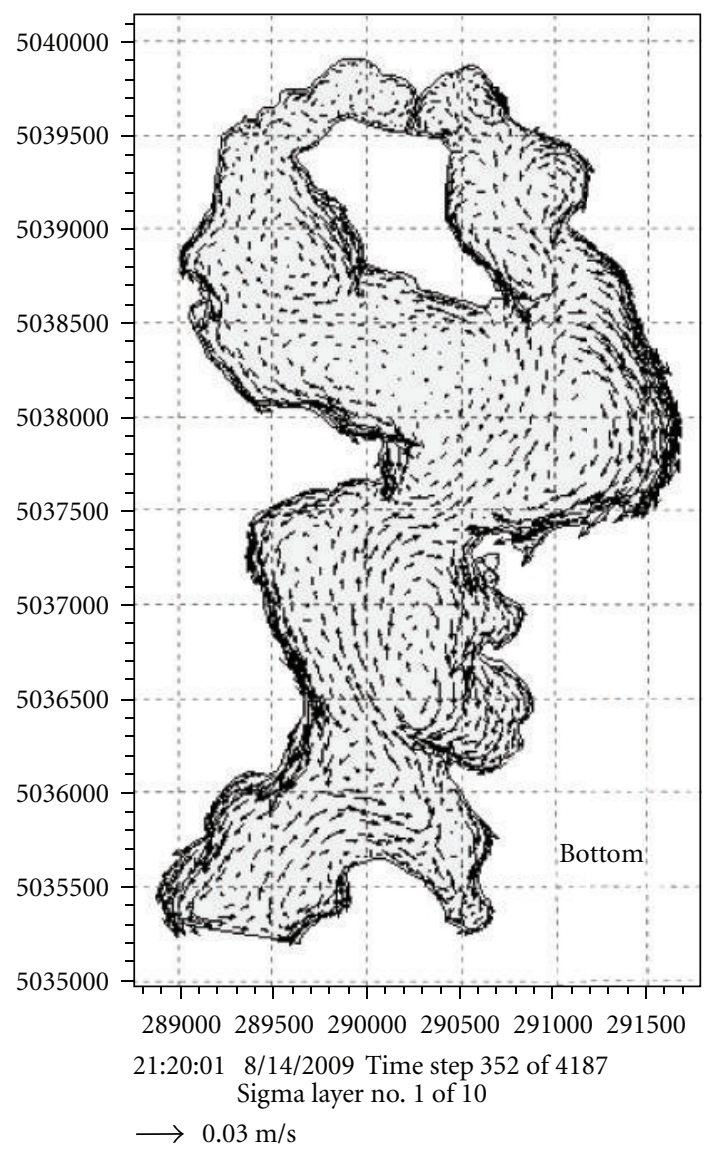

(b)

FIgURE 5: The simulated wind-induced general flow pattern in the surface and bottom layers.

of the water temperature on flow movements even though it was not expected to be strong in this case. A constant horizontal eddy viscosity $\left(0.002 \mathrm{~m}^{2} / \mathrm{s}\right)$ was found to be an adequate value [7] for simulating mainly wind-induced flow and was used in this study to save computer running time. The widely used-two equation $k-\varepsilon$ formulation was adopted for calculating the vertical eddy viscosity. A constant drag coefficient of 0.01 was specified in the quadratic drag formula for bed resistance calculation. The wind forces as shown in Figure 2 vary in time and are constant in the domain. Initially, the model was set at rest with all velocity components being zero and temperature varying in space, the model initial temperature distribution was obtained by interpolating measured temperatures from each of the deployed instruments.

The boundary condition of the numerical model was relatively simple in this study because the modeled domain is surrounded by the closed shoreline except for the narrow opening at the south end. Since no detailed measurements are available along the south end open boundary for the purpose of reconstructing a realistic hydrodynamic open boundary condition and the flows at the south end open boundary are unlikely to have a strong influence on the hydraulic conditions in the region around Mask Island due to the distance of the south boundary from Mask Island, it should be reasonable to treat the south end open boundary as a closed boundary. There are a few small streams flowing into the north basin of the lake; the inflow rates vary with weather conditions and did not need to be monitored because they were not expected to have a strong influence on the flow conditions in the study area. Therefore, no inflows from small streams were included in the simulations. The constant drinking water intake rate of $0.0058 \mathrm{~m}^{3} / \mathrm{s}$ and sewage discharge rate of $0.0064 \mathrm{~m}^{3} / \mathrm{s}$ were assigned in the model based on the data provided by the local WTP and STP operators.

Figure 4 shows the comparison of the time series of the measured and simulated velocities at different depths at the ADCP measurement location. Due to the high-frequency noises in the measured velocities, a 4-hour lowpass timing filter was applied to the measured current data in all comparison plots. Apparently, the agreement in the $y$ direction is better than in the $x$ direction, which could be possibly attributed to the stronger $y$ wind component because the lake flow is mainly controlled by the local wind and the lake orientation is roughly along the $y$ axis. Since any numerical model is an approximation of an analytical solution with inherent truncation and other numerical errors, in general, the reliability of modeling results will increase with 


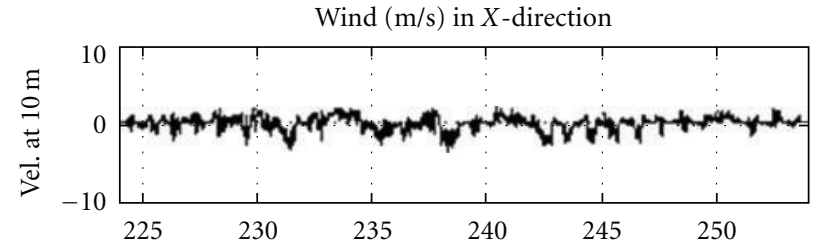

(a)

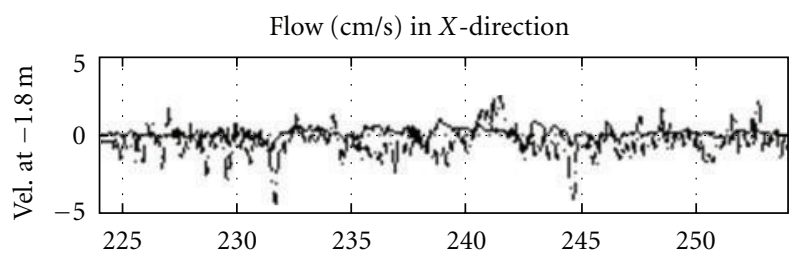

(c)

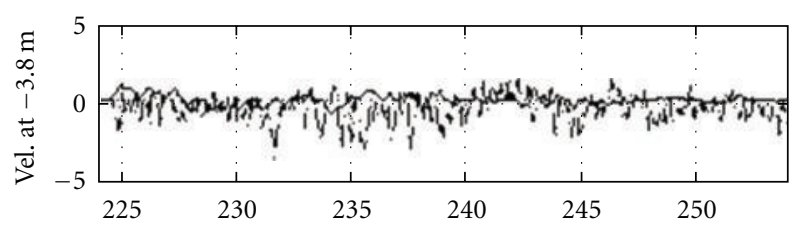

(e)

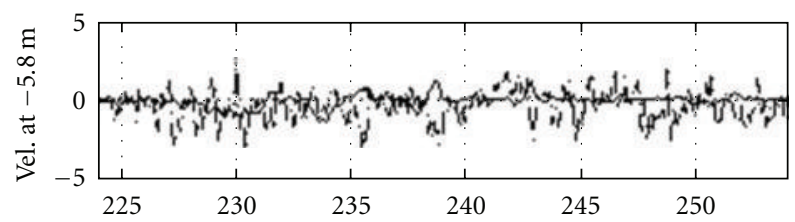

(g)

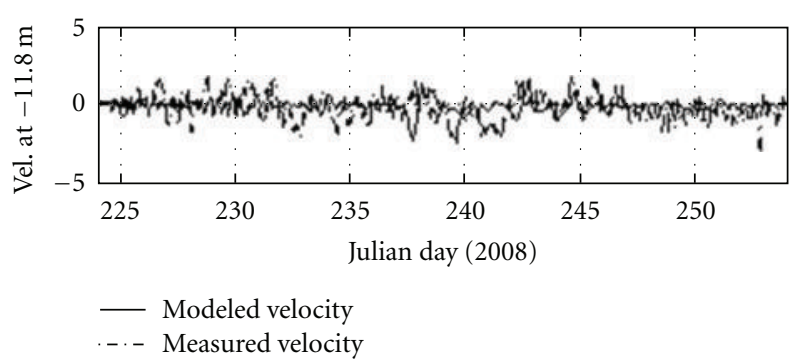

(i)

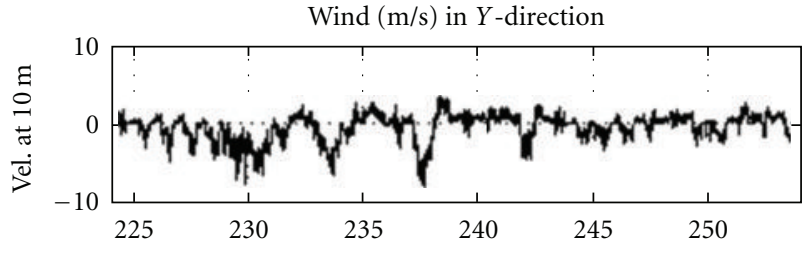

(b)

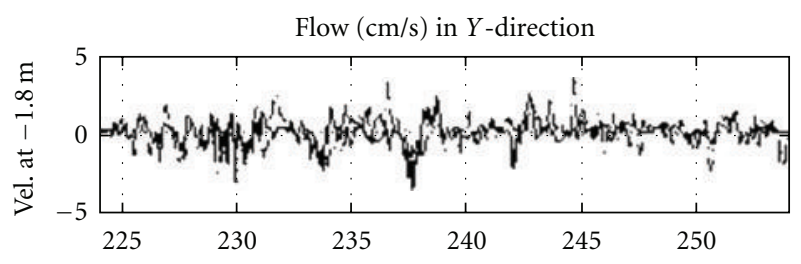

(d)

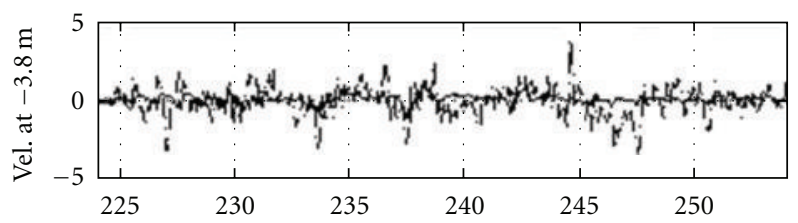

(f)

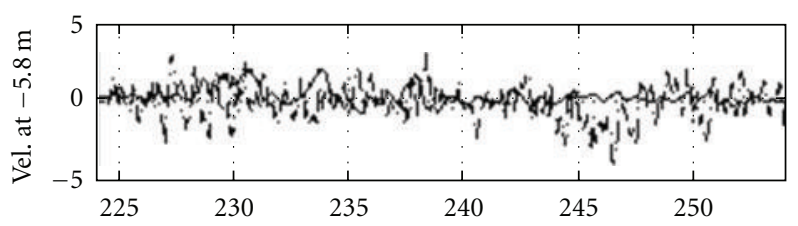

(h)

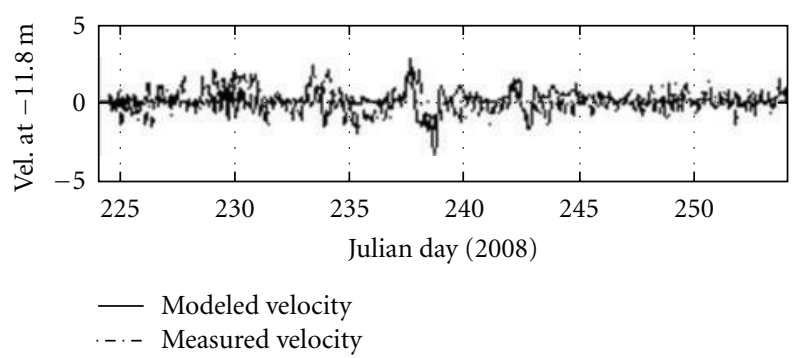

(j)

FIGURE 6: Comparison of the modeled and measured flow velocities at different water depths; the modeling results are from the simulation without the heat effects on water density.

the increase of model driving forces. Realistically, for windinduced flow, any 3D hydrodynamic open water models can only produce consistent and reliable results if the flow velocity is larger than a few centimeters. Unfortunately, there is no strong meteorological event being recorded during the period of instrument deployment, which was also reflected from the amplitude of the measured flow velocity, the maximum recorded current velocity after passing the 4-hour low-pass filter is no more than $3 \mathrm{~cm} / \mathrm{s}$. Even though the numerical model closely reaches its applicable limits, it still reasonably duplicated the few captured weak events.
Several parameters in the model were adjusted and optimized, such as the bottom friction coefficient, calculation scheme for the horizontal and vertical eddies, and the adjustment for the effects of the land and obstacles on the wind speed, but the modeled results did not show significant changes. As expected from the simulation of wind-induced flows, agreements between the modeled and measured flows are the best in the surface layer. However, the comparisons also show a surprisingly good agreement in the bottom layer, which indicates that the model can well reproduce the bottom reverse flow. The flows in the middle 


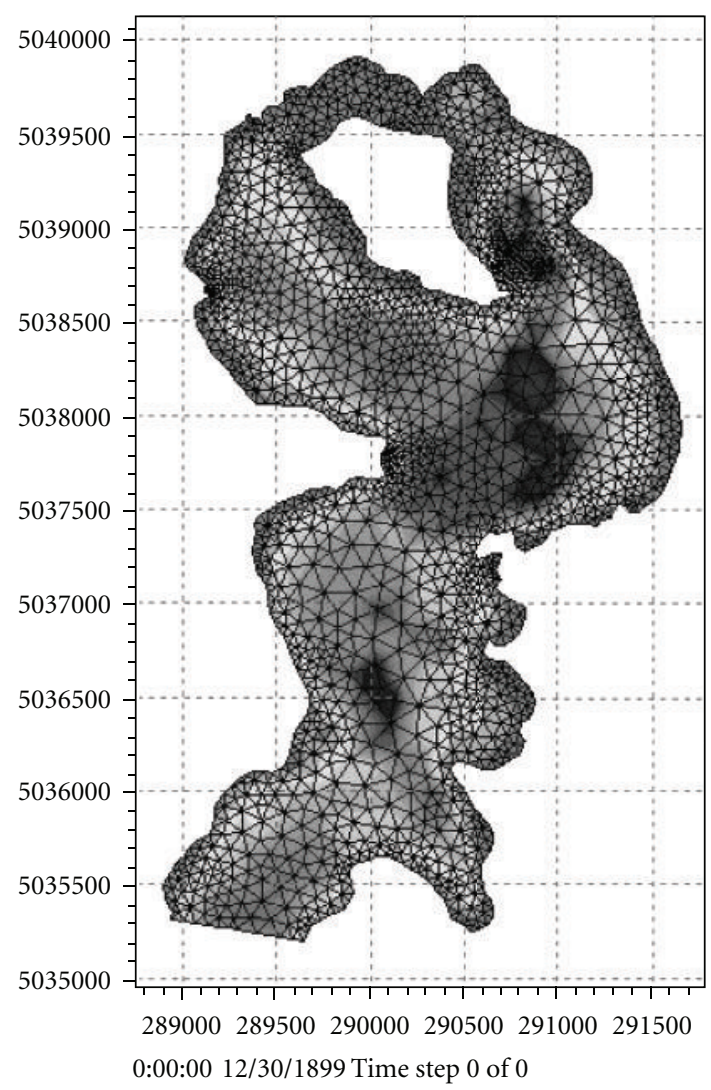

Figure 7: The finer mesh used to evaluate dependence of the modeling accuracy on mesh resolution.

layer, in general, are difficult to be duplicated by numerical simulation under weak wind conditions because weak energy can be overdampened (lost) in the numerical calculation of the energy transferring down to the deeper water and the depth at which the bottom reverse flow begins has to be predicted accurately.

Also, as mentioned previously, winds tend to induce a strong and consistent coastal (boundary) current in a closed basin. From Figure 1, it can be seen that the location of the ADCP is in the middle of the lake, where the flows are generally not very strong and vary in direction more often because of lack of restriction from the boundary. Therefore, it is always more of a challenge for a model to accurately simulate currents in the middle of the lake than those in the coastal region. Figure 5 shows the simulated wind-induced general flow patterns in the surface and bottom layers in the north closed basin. It can be clearly seen that the boundary currents are much stronger than the currents in the middle of the lake in both of the surface and bottom layers.

Generally, in a small-sized lake, the flow movements generated by baroclinic force due to the stratified water column are a secondary component and much weaker than flow velocity induced by wind force and the slope of the water-free surface because of much weaker forces produced by flow density differences in the horizontal direction. A separate run without influences of water temperature on the water density was carried out to examine the simulation results with and without heat effects and the results are shown in Figure 6. Compared to model results in Figure 4, the differences between simulations with (in Figure 4) and without (in Figure 6) water temperature influences are very small and insignificant. If one closely compares the simulated curves in the surface and bottom layers in the $y$ direction in the two figures, it is not difficult to find that the agreements between measurements and simulations would be better in the cases without the heat effect than those with the heat influence. The possible reasons are that (1) application of the surface heat flux in the model requires the user to provide the information of the percentage of cloud cover, which was not available in this study; the default value of $70 \%$ cloud coverage was used in the simulation, (2) accurately simulating the temperature distributions in the water column is not a trivial task. The errors associated with heat transport simulation when including heat effects can sometimes have a larger negative influence than the heat contribution itself. Since the modeled flows with and without heat influence are about the same, to reduce the model run time, in all of the following simulations, the surface heat flux was not included in the modeling.

It is well known that the model mesh resolution could have large effects on the modeling results. To examine this influence, a new mesh, displayed in Figure 7, with higher horizontal and vertical resolutions was tested and results are shown in Figure 8. The new mesh has 1858 nodes, 3264 elements, and 16 layers in the vertical. It takes more than 10times longer to run the model using this mesh compared to the mesh shown in Figure 3 because much smaller time steps have to be adopted, as well as more nodal points need to be calculated. Compared to the curves in Figure 4 or Figure 6, the curves in Figure 8 have greater variation and larger simulated velocities, which is expected from the simulation using a finer mesh because of less numerical dampening (averaging). In general, there are no obvious improvements from the simulation using a finer mesh, which implies that the low-resolution mesh used earlier should be adequate to produce reasonable simulation accuracy.

In summary, it is always a challenge for any open-water 3D hydrodynamic model to accurately reproduce weak windinduced flows in a small closed basin because of the nature of numerical errors and relatively rapidly changing and complex flow patterns. In spite of these difficulties, this model still reasonably captured most small metrological events recorded during the period of the field data collection, especially for the currents in the surface and bottom layers. The model may show a better performance if the comparisons between model outputs and measurements were made in the region near the shore. Considering that the applied model has been widely used in many different applications, it has been well-verified in other studies [7-11], and also, the model used in this study is mainly for comparison purposes under much stronger winds. The adopted model should thus be reasonably capable of producing predictions of hydraulic condition changes in the study area under various causeway structures and wind conditions. 


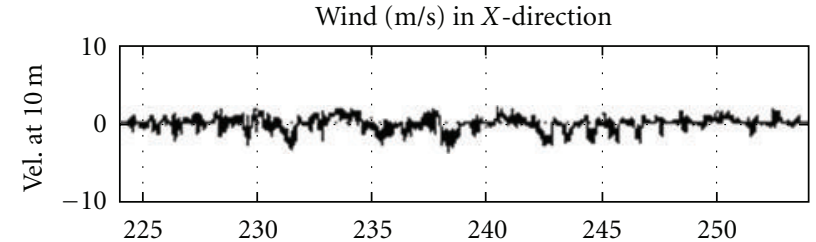

(a)

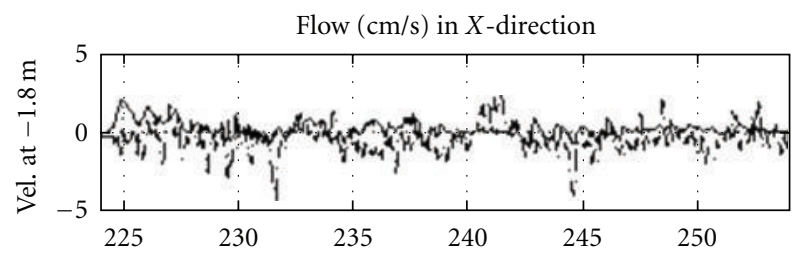

(c)

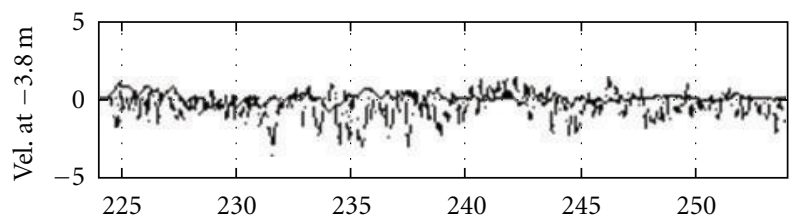

(e)

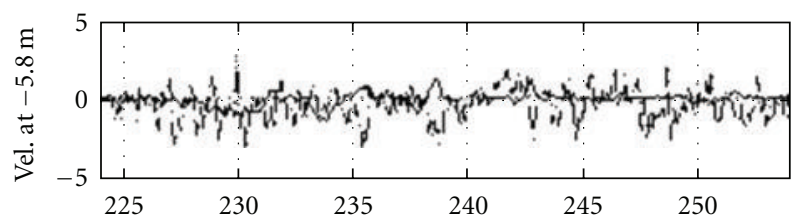

(g)

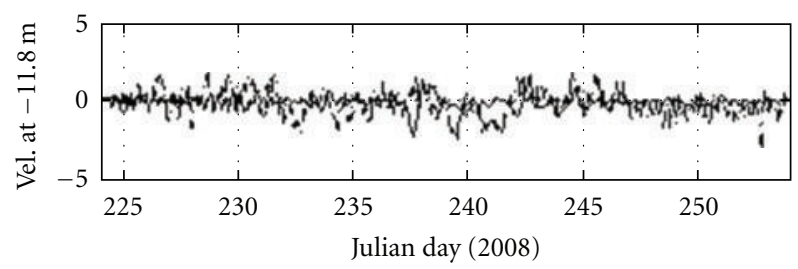

- Modeled velocity

. - - Measured velocity

(i)

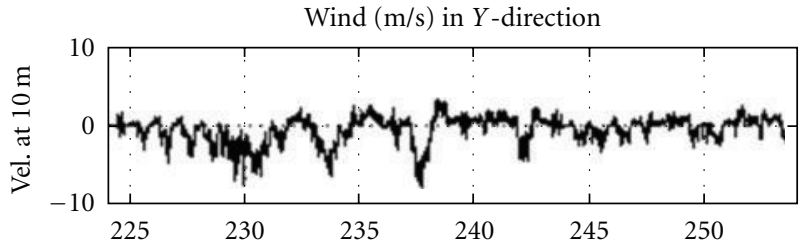

(b)

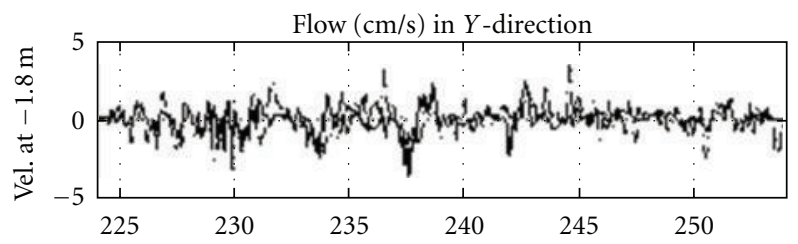

(d)

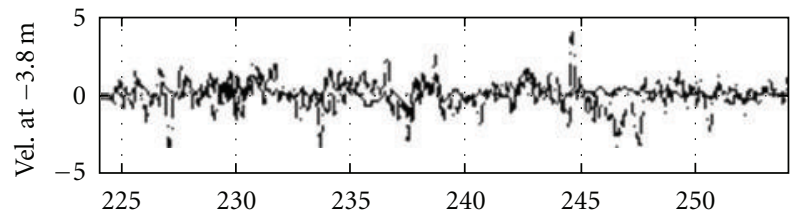

(f)

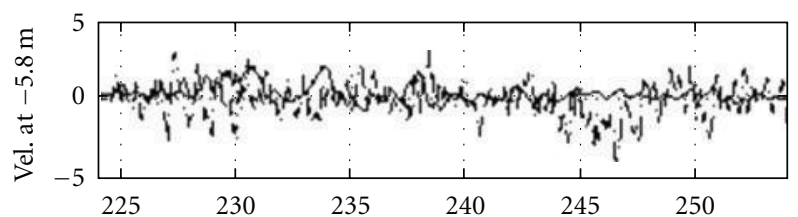

(h)

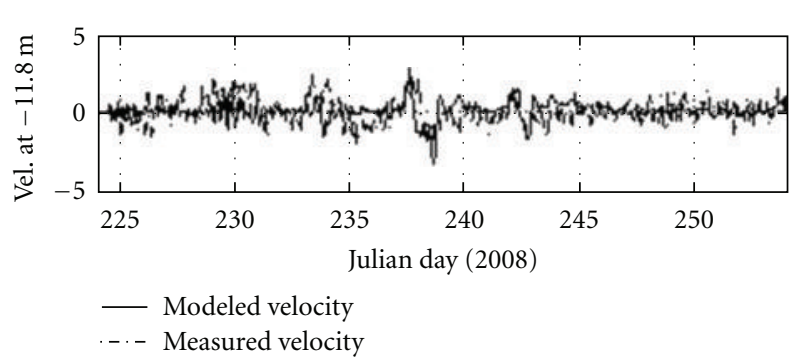

(j)

FIGURE 8: Comparison of the modeled and measured flow velocities at different water depths; the modeling results are from the simulation with a finer model mesh as shown in Figure 7.

\section{Modeling Results and Discussions}

As mentioned before, the main purpose of this hydraulic modeling study was to investigate the best way to improve the hydraulic conditions around Mask Island by opening the causeway to increase the flow circulation. Flow conditions under several alternative causeway structures and winds will be presented below.

\subsection{Removal of the Causeway}

5.1.1. Under Natural Wind. In this scenario, it assumes that the causeway is replaced by a long bridge, which would create the maximum possible flow exchange between the two sides of Mask Island. The first test was conducted with the measured natural wind and the mesh used in this test is shown in Figure 9. It can be seen that the mesh in Figure 9 is very similar to the one used in the simulation with the causeway in place (in Figure 3), therefore, any differences of the modeling results with and without the causeway should not be due to differences in the mesh used. The time series of the simulated net amount of flows passing through the cross-section along the existing causeway position (refer to the white line in Figure 9) is displayed in Figure 10. In order to easily analyze the relationship between wind direction and flow flux through the new opening, the $x$ and $y$ wind 


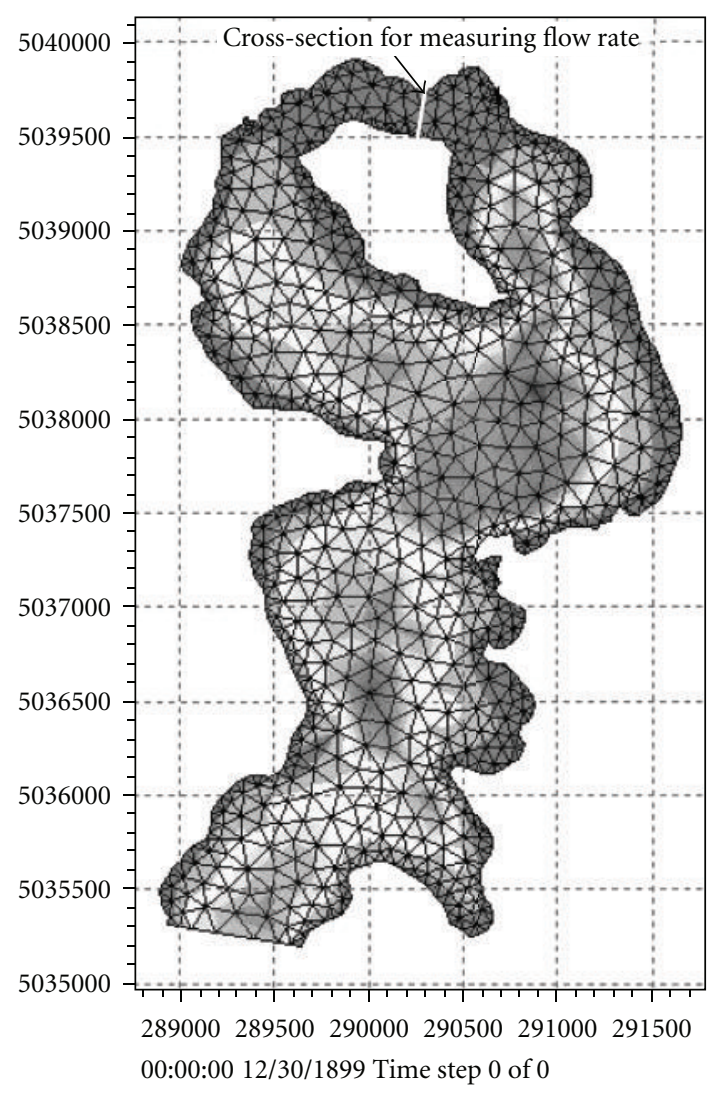

FIGURE 9: The mesh without including the causeway; the white straight line at the location of the existing causeway indicates a cross-section location where the total amounts of the simulated passing through flows are calculated.

components are plotted in the top and middle panels and the flow flux changing with time is plotted in the bottom panel in Figure 10, respectively. The maximum and average flow rates are $20 \mathrm{~m}^{3} / \mathrm{s}$ and $4.65 \mathrm{~m}^{3} / \mathrm{s}$, respectively. When comparing the changes of flow flux rate with the changes of the wind direction, we find that the flow flux through the examined cross-section is mainly controlled by the $x$ wind component even though the measured wind in the $x$ direction, in general, is much weaker than the wind in the $y$ direction during the measured period. If plotting the $x$ wind component curve with the flow flux curve together, they follow each other very well, which is not the case for the $y$ wind component. These results are not really unexpected because the direction of the majority of the flows passing through the examined cross-section would roughly align with the $x$ axis. Also, water depth in the causeway region is relatively shallow (the average water depth is about $2 \mathrm{~m}$ ); the wind would be a main force to determine the flow patterns. The results in Figure 10 also imply that the strong flows generated by a strong north wind (negative $y$ component) at other places in the lake do not directly transfer to the flow movement in the causeway region. The possible explanation is that flow could not circulate around Mask Island even under a strong north wind and the complete removal of the causeway, because of the relatively symmetric geography around the island. The simulated flow patterns in the surface and bottom layers on the

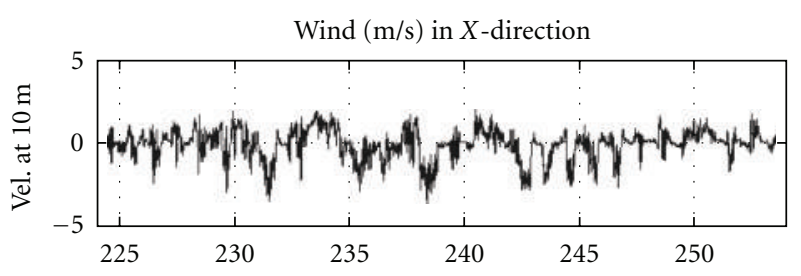

(a)

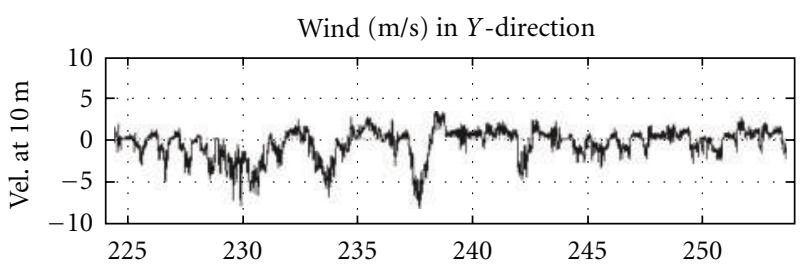

(b)

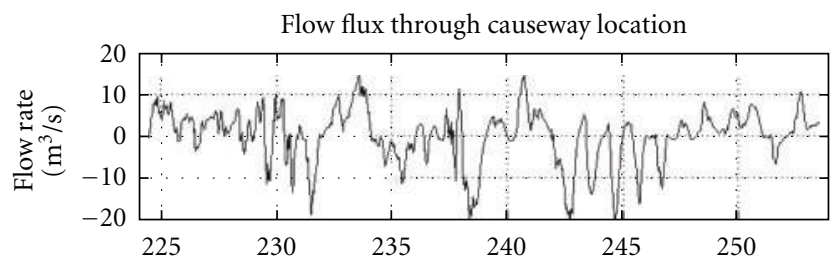

(c)

FIGURE 10: Time series of the exchange flows passing through the cross-section at a location indicated by the white straight line in Figure 9.

Julian day 237.7 (having the strongest recorded north wind) in Figure 11 confirms the above explanation. Both the surface and bottom flows on the two opposite sides are in similar directions. With such a flow pattern, it is difficult to form a large circulation pattern around the island.

During the recorded period (summer) there was no strong south wind recorded as is generally the case in this region, therefore, the hydraulic conditions generated by strong south winds were not considered to very important in this study and will not be examined further.

Figure 12 is a comparison of the simulated flows at different depths near the WTP intake with and without the causeway included in the simulations. The curves from the two simulations look similar, but for the case without the causeway, the simulated velocity is slightly larger in the surface layer and smaller in the bottom layer. This indicates that under certain circumstances, the newly generated flows due to the removal of the causeway do have some impacts on the flow conditions around Mask Island, even at a location reasonably far from the causeway. More detailed studies will be conducted in the following sections focusing only on the east or west driving winds with different wind speeds and the proposed configurations of the causeway.

5.1.2. Under Strong Constant East Wind. The STP discharge is located on the east side of Mask Island and flow rates passing through the existing causeway region were not expected to be really different between the winds from the east and west, in the following simulations. The $10 \mathrm{~m} / \mathrm{s}$ constant 


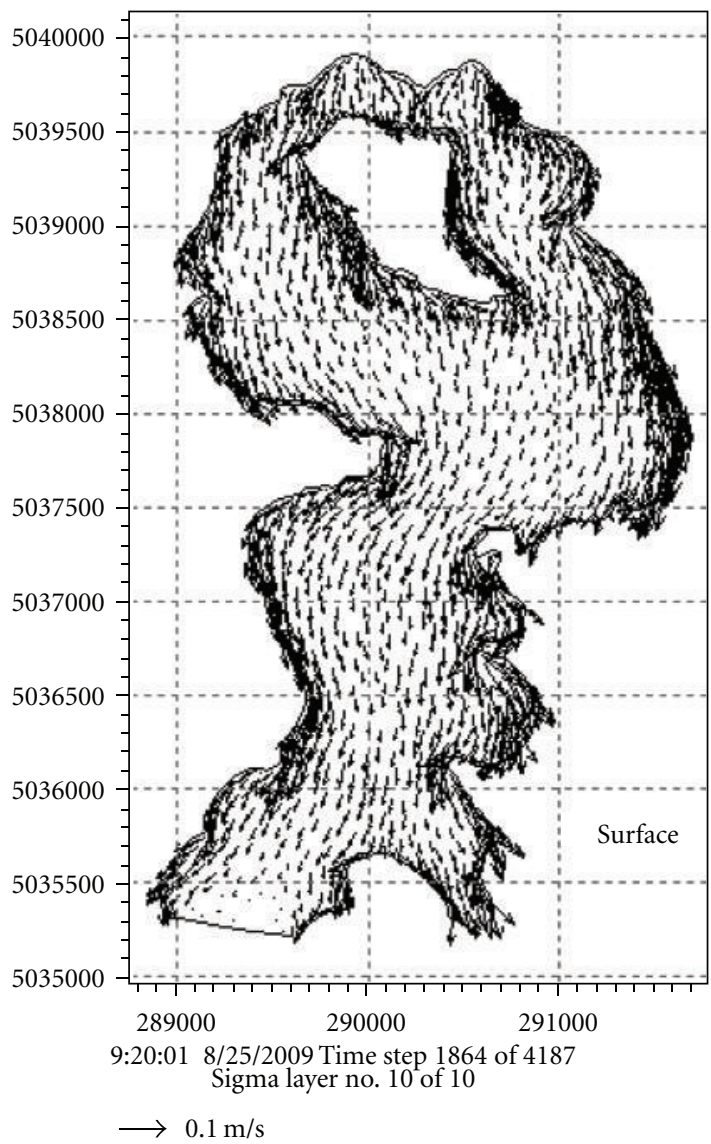

(a)

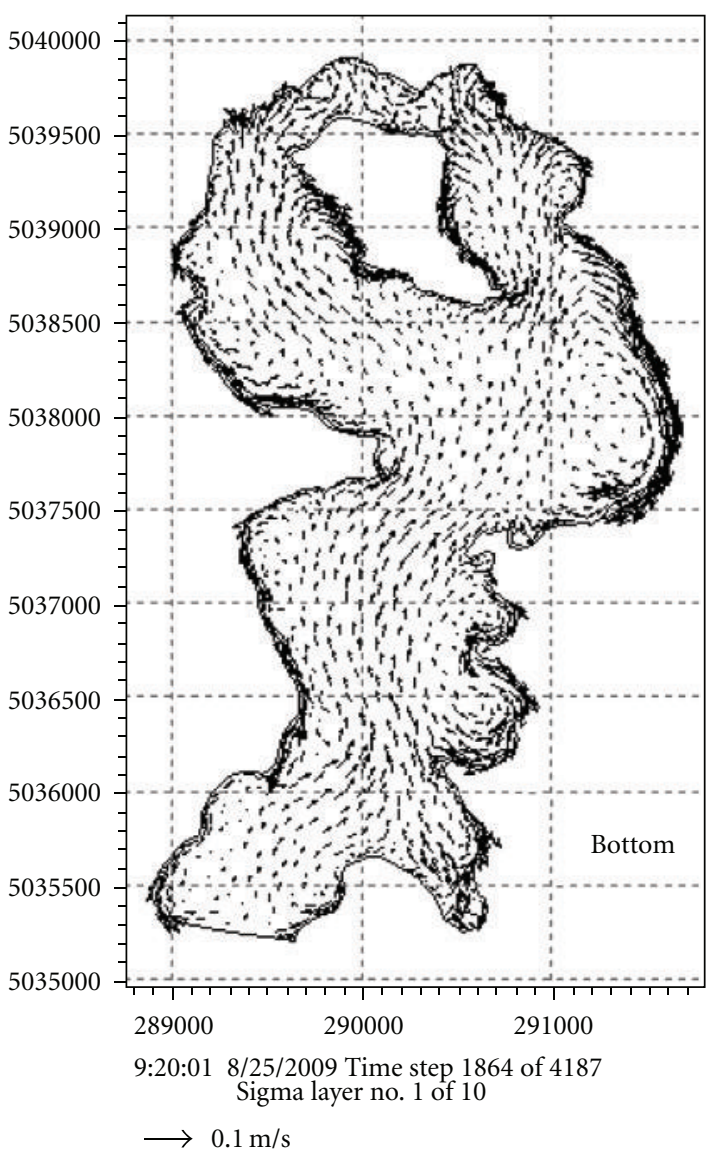

(b)

FiguRE 11: The simulated surface and bottom flow patterns at the Julian 237.7 day (having the strongest recorded north wind).

east wind was used for the purpose of investigating the potential effects of the STP discharge water on water quality on the west side of Mask Island, as well as the exchange flow rates and hydraulic conditions in the causeway region. Choosing the wind speed of $10 \mathrm{~m} / \mathrm{s}$ in the modeling run was based on the recorded maximum wind speed during the experiment period.

Figure 13 shows the flow rate passing through the causeway region changing with time. It shows that under a strong constant east wind, after less than 2 hours the flow rate can reach as high as $80 \mathrm{~m}^{3} / \mathrm{s}$ if the causeway is fully removed. Such a high flow rate will strongly stimulate the flow movements in the shallow water region around the causeway, which can be clearly evidenced by the flow patterns in Figure 14. The top and bottom panels display the simulated flow in the surface and bottom layers, respectively, after simulating 5 hours of realtime (starting from rest). The flows on the surface layer mainly follow the wind direction, as expected, and the flow velocity can be greater than $20 \mathrm{~cm} / \mathrm{s}$. After 5 hours, the discharged water from the STP can reach most parts of the western side of Mask Island as indicated by background colour of specific conductivity in Figure 14, which may cause concerns even though the concentration can be very low when reaching the other side of the island.
However, the stimulated circulation would reduce the chance of algae growing in the shallow water region.

It is interesting to note that the bottom flow patterns on the bottom panel in Figure 14 shows that the bottomdischarged, higher-concentrated water from the STP does not travel very far from the original released location. This can be understood from the displayed flow patterns in the same plot. Because the mouth of the discharge pipe is located in the deep hole of the lake bottom ( $15 \mathrm{~m}$ below the surface, refer to Figure 3), the surrounding steep bottom slope will restrict the bottom flow from dissipating freely, and also the winds have much less influence on flow movements in the deep water. The ambient flow at STP discharge location, as a carrier of the discharged substances, could be weak even under a strong wind condition, resulting in the discharged plume being retained in the vicinity of the discharge mouth.

The bottom flows in Figure 14 also show that a large counter-clockwise circulation around Mask Island is generated due to that in the relatively shallow water region around the existing causeway, a westwards vertically uniform flow pattern is established by the strong east wind, and the surface flows in the region of the southern part of Mask Island also follows wind direction. However, according to the mass conservation requirement, flow has to return towards 


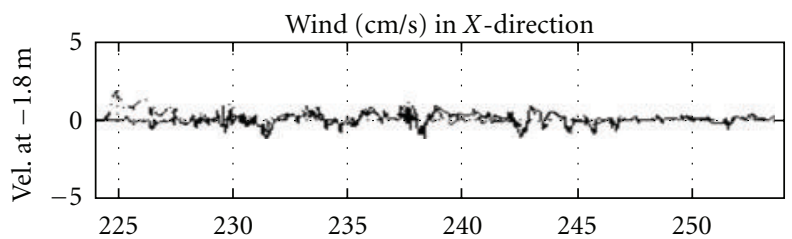

(a)

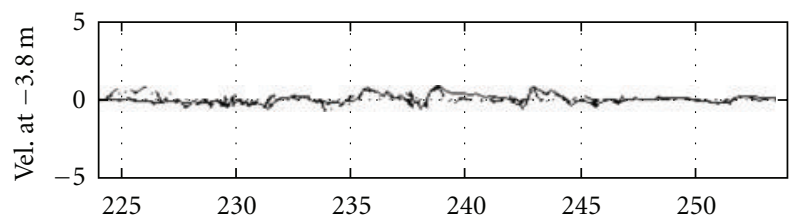

(c)

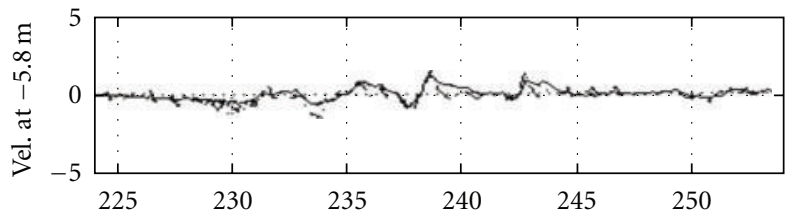

(e)

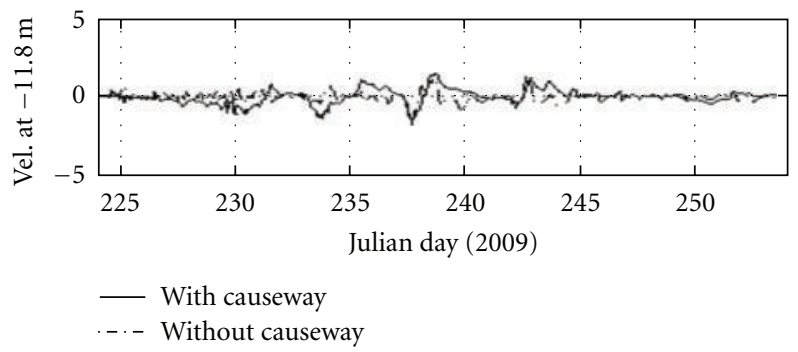

(g)

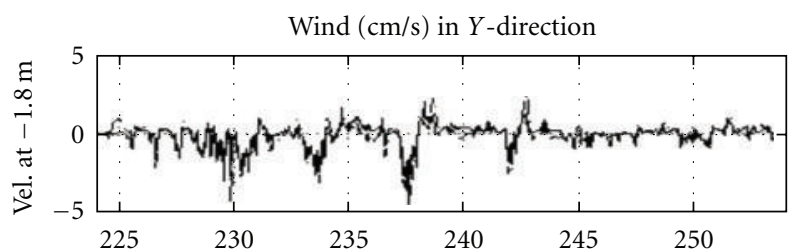

(b)

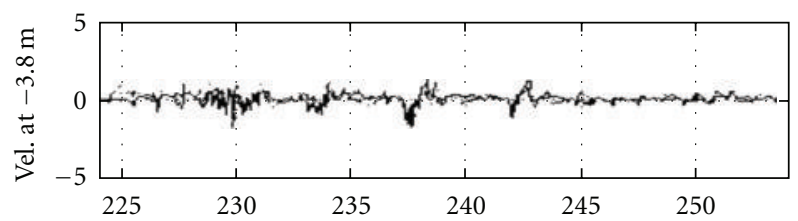

(d)

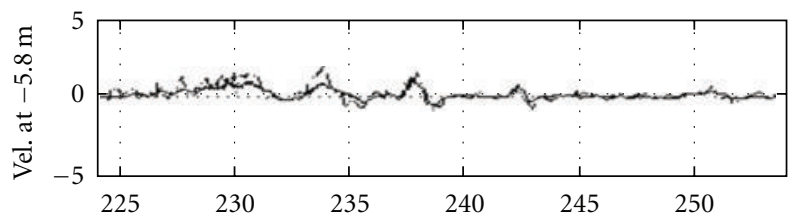

(f)

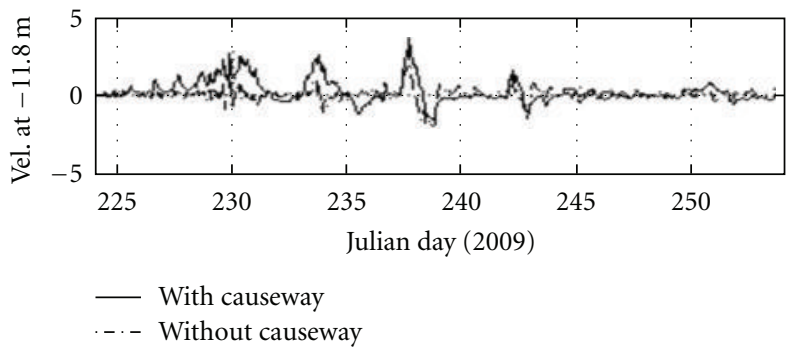

(h)

Figure 12: The comparisons of the simulated flows in the different depths at the WTP intake location with and without the causeway included in the simulations.

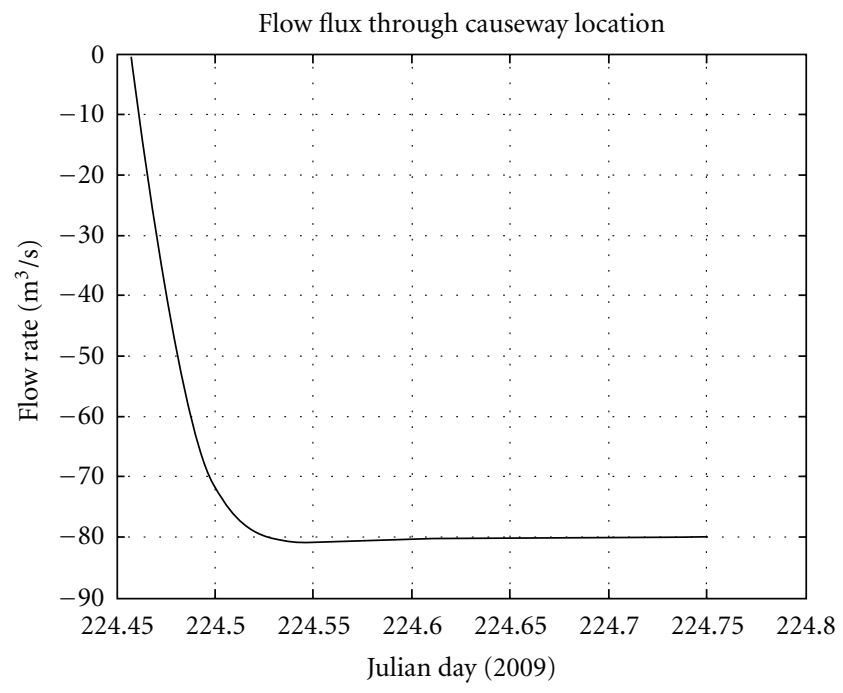

Figure 13: The exchange flow rate $\left(\mathrm{m}^{3} / \mathrm{s}\right)$ passing through the causeway region changing with time under strong constant east wind of $10 \mathrm{~m} / \mathrm{s}$. the east from the bottom. These two flow patterns form a large bottom circulation around Mask Island as displayed in Figure 14.

5.2. Causeway with a Single Opening. This scenario is to test that if a 15-meter-wide bridge were to be constructed in the middle of the causeway, how would it change the local flow conditions and would it help to generate a strong westward flow under an east wind in order to produce a large circulation pattern around the island. As in the previous case, both the measured and $10 \mathrm{~m} / \mathrm{s}$ constant east winds were used in the simulations and the model mesh around the causeway area for testing this scenario is displayed in Figure 15.

5.2.1. Under Natural Wind. The time series of the simulated flow rates passing through a 15-meter-wide opening and flow patterns in the causeway area on the Julian day 238.1 (having the strongest recorded east wind) are presented in Figures 16 and 17, respectively. Under a strong east wind, the maximum flow rate reaches $2.6 \mathrm{~m}^{3} / \mathrm{s}$ and the average flow rate is around $0.57 \mathrm{~m}^{3} / \mathrm{s}$ during the tested 30 -day period. 


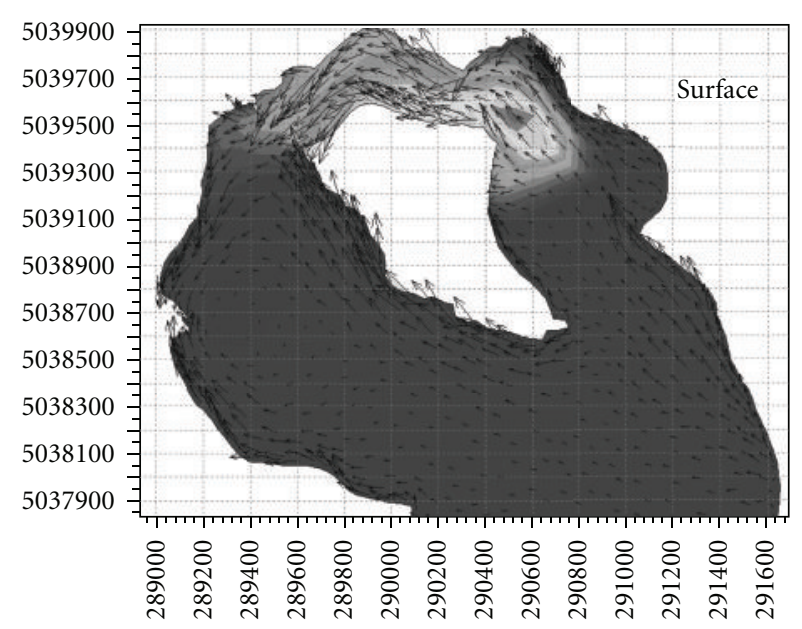

15:40:00 8/12/2009 Time step 30 of 43 Sigma layer no. 10 of 10

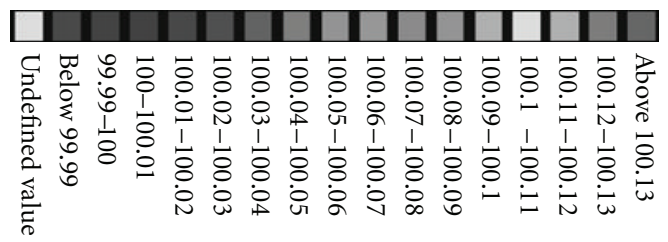

Concentration component $1\left(\mathrm{~kg} / \mathrm{m}^{3}\right)$

$\longrightarrow 0.2 \mathrm{~m} / \mathrm{s}$

(a)

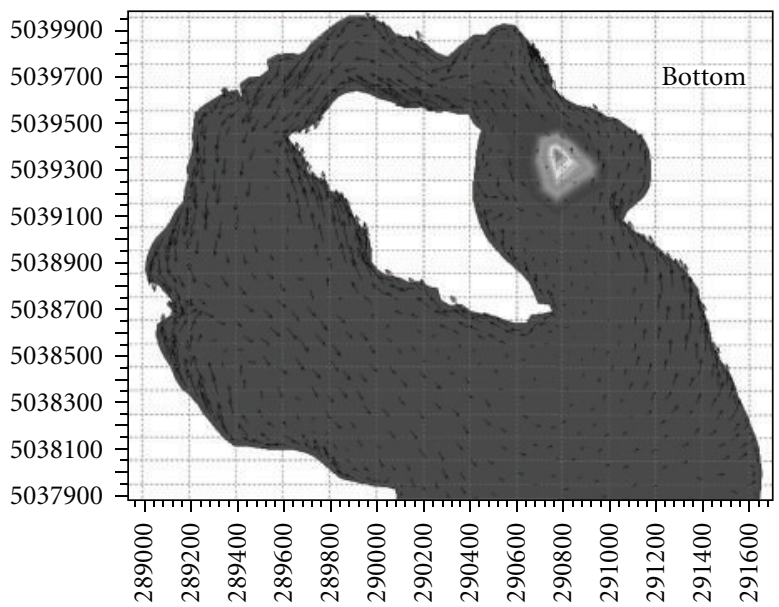

15:40:00 8/12/2009 Time step 30 of 43 Sigma layer no. 1 of 10

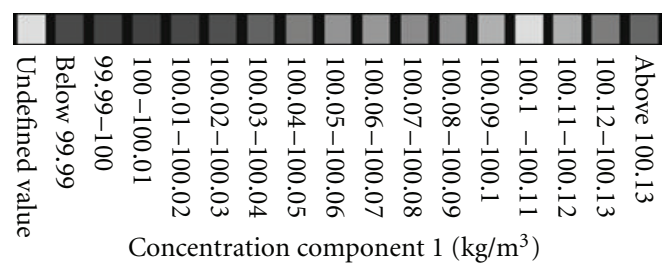

$\longrightarrow 0.2 \mathrm{~m} / \mathrm{s}$

FIGURE 14: The simulated flow patterns in the surface and bottom layers, driven by a constant east wind of $10 \mathrm{~m} / \mathrm{s}$ after model simulates for 5 hours in realtime starting from rest.

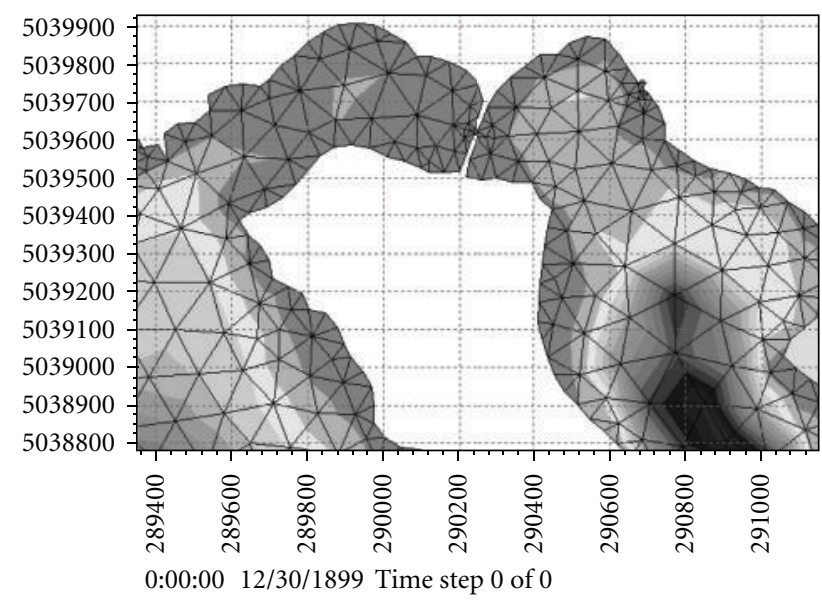

FIGURE 15: The mesh in the causeway area used for investigation of the hydraulic conditions under a causeway with a single opening.

Similar flow patterns have been developed, the surface flows follow the wind direction, and in the bottom layer, because the opening is not wide enough, the hydraulic pressure generated by the tilted water-free surface on the east side of the causeway drives the flow against the wind direction. The surface flow is stronger than the bottom flow as in most cases for wind-induced flows, but in general, the flow is very weak and the velocity is less than $5 \mathrm{~cm} / \mathrm{s}$. By comparing the same

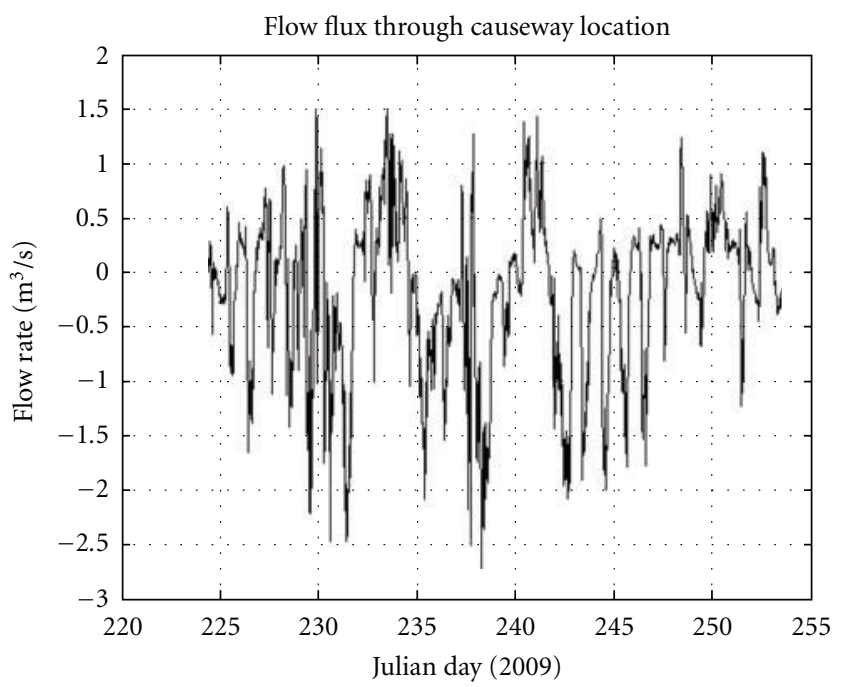

Figure 16: The exchange flow rate $\left(\mathrm{m}^{3} / \mathrm{s}\right)$ through a 15 -meter-wide opening in the middle of the causeway induced by the measured natural wind.

moment flow patterns generated with the closed causeway configuration, as shown in Figure 18, it shows that there is no real difference between the two flow patterns, except that the return bottom flow in the vicinity of the left side of the opening may become weaker due to the "pushing" 


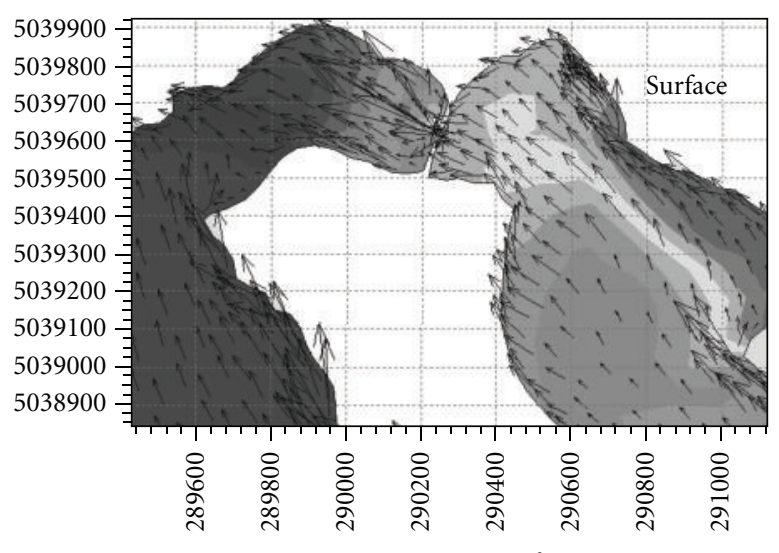

6:20:00 8/26/2009 Time step 1990 of 4188 Sigma layer no. 10 of 10

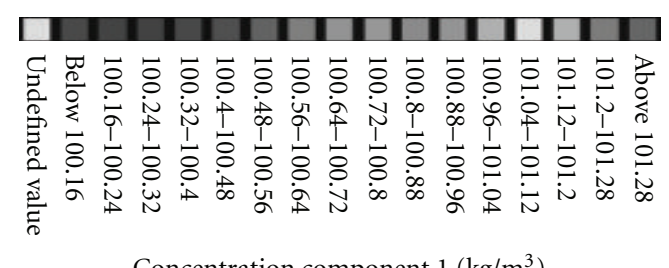

Concentration component $1\left(\mathrm{~kg} / \mathrm{m}^{3}\right)$

$\longrightarrow 0.02 \mathrm{~m} / \mathrm{s}$

(a)

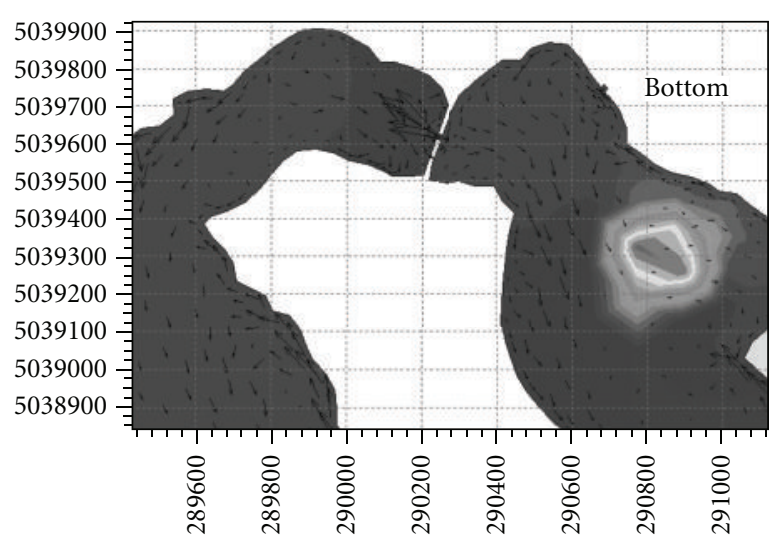

6:20:00 8/26/2009 Time step 1990 of 4188 Sigma layer no. 1 of 10

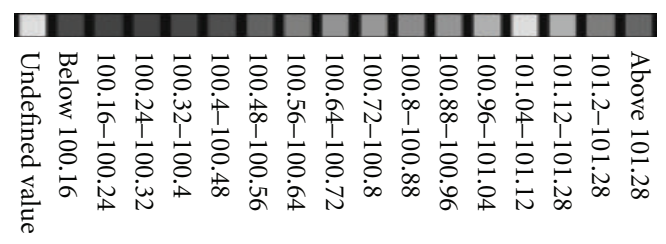

Concentration component $1\left(\mathrm{~kg} / \mathrm{m}^{3}\right)$

$\longrightarrow 0.02 \mathrm{~m} / \mathrm{s}$

(b)

FIGURE 17: Simulated flow patterns in the causeway area on the Julian day 238.1 (having the strongest recorded east wind) with a 15-meterwide opening in the middle of the causeway.

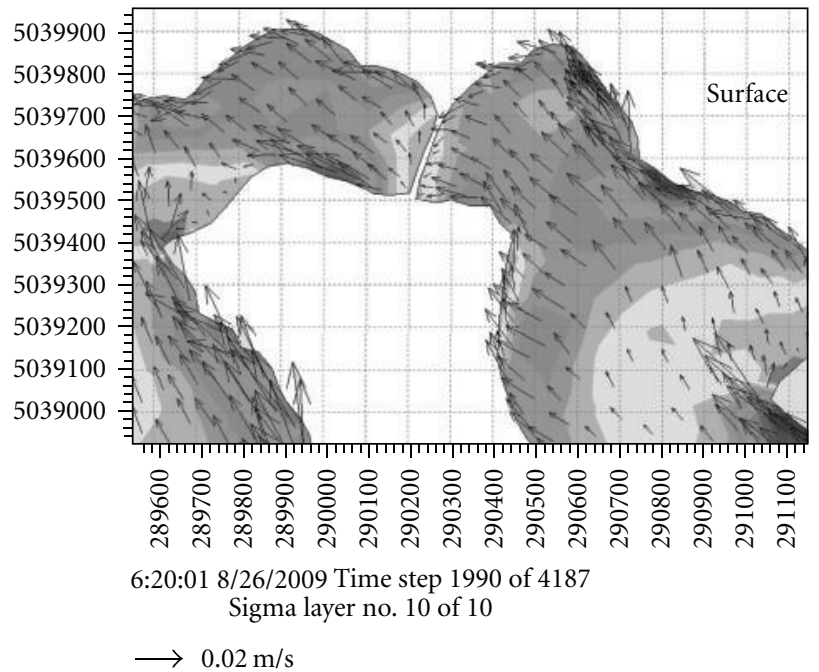

(a)

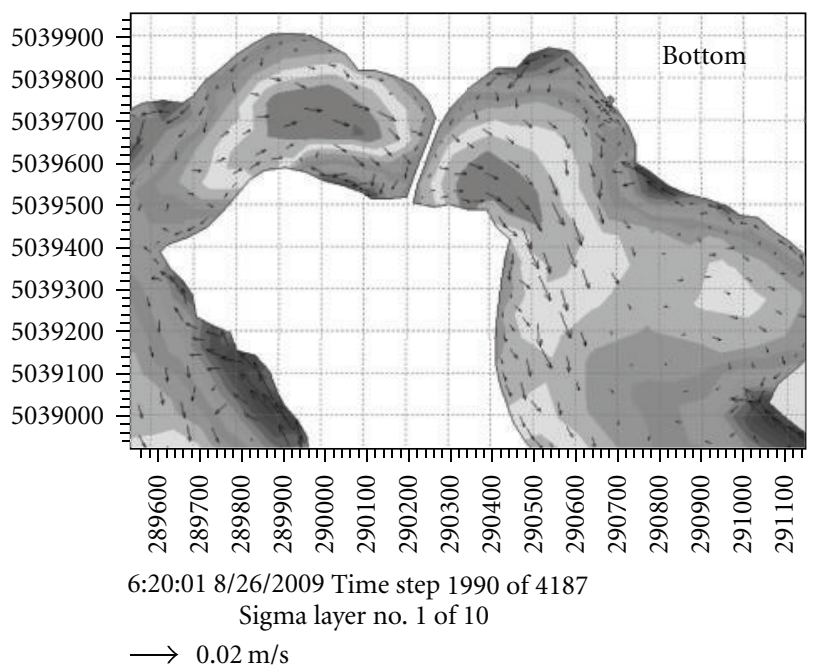

(b)

FIGURE 18: Simulated flow patterns in the causeway area on the Julian day 238.1 (having the strongest recorded east wind) under a closed causeway in place.

force generated by the flow-passing through. Such a strong similarity in flow pattern indicates that a 15-meter-wide opening may not be large enough to have a strong impact on the surrounding flow conditions.

5.2.2. Under Strong $10 \mathrm{~m} / \mathrm{s}$ Constant East Wind. Figure 19 displays the flow rate generated by a $10 \mathrm{~m} / \mathrm{s}$ constant east wind. After the wind blows for about half an hour, the exchange flow rate reaches a constant maximum value of $7 \mathrm{~m}^{3} / \mathrm{s}$ from $0 \mathrm{~m}^{3} / \mathrm{s}$. The strong constant east wind may generate large passing flows, but it still may not be large enough to have significant influence on the local flow conditions, because surrounding flows under a strong east wind also become very active as indicated by the simulated flow 


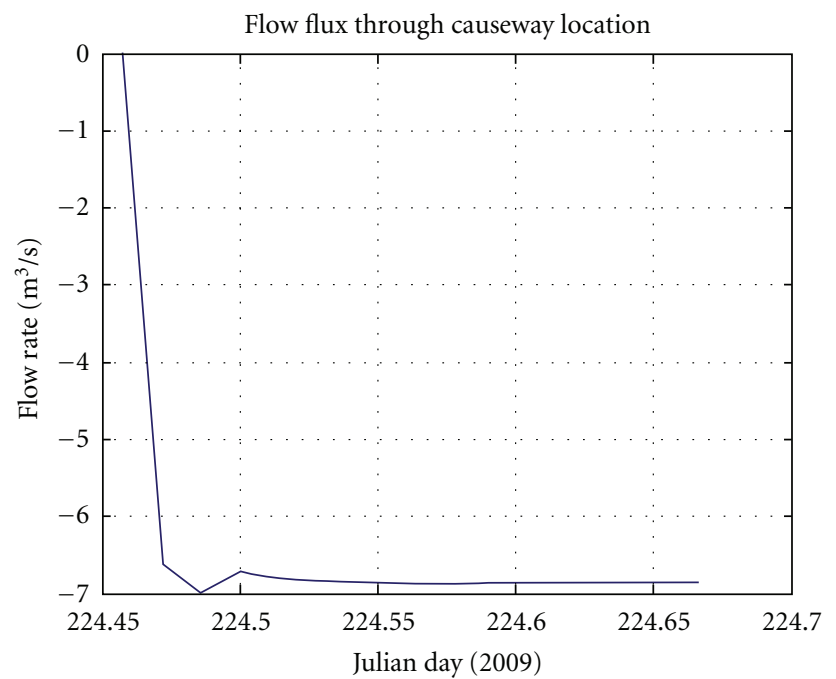

Figure 19: The exchange flow rate through a 15-meter-wide opening in the middle of the causeway induced by a constant east wind of $10 \mathrm{~m} / \mathrm{s}$.
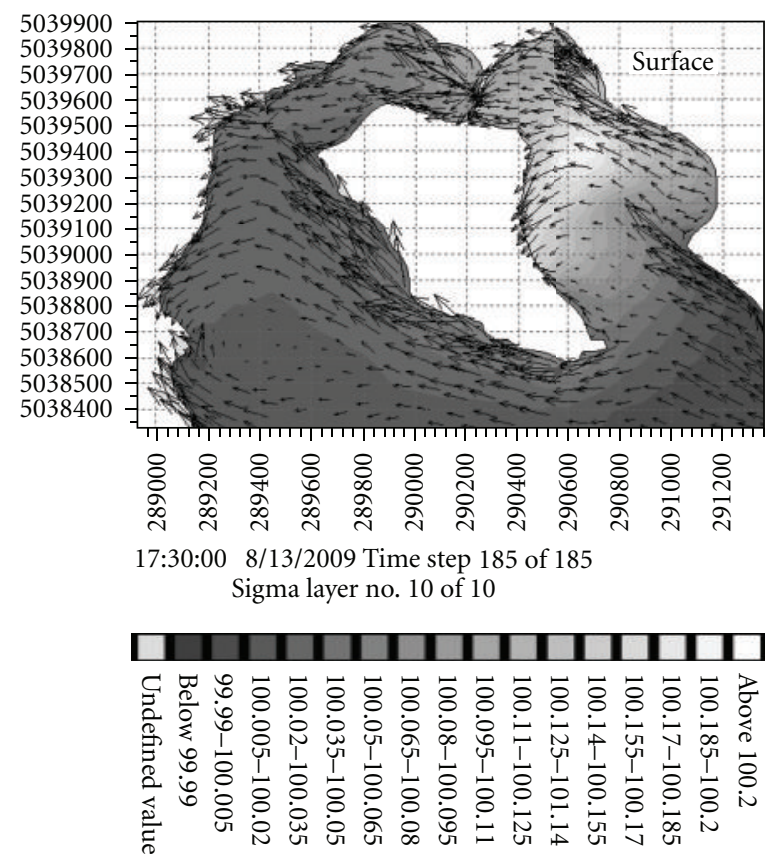
$\longrightarrow 0.05 \mathrm{~m} / \mathrm{s}$

Concentration component $1\left(\mathrm{~kg} / \mathrm{m}^{3}\right)$

(a)
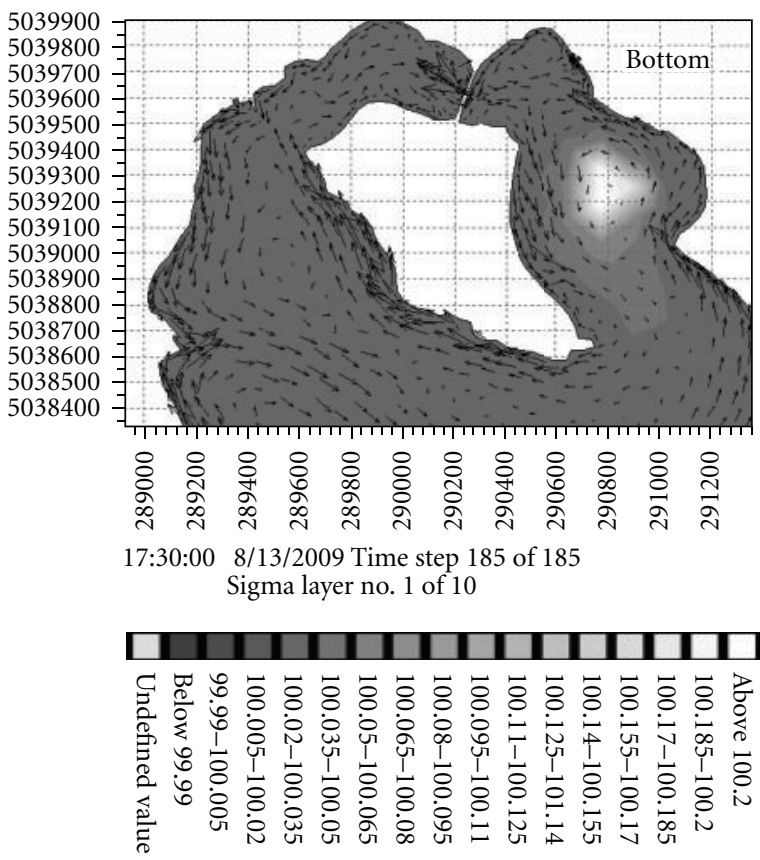

$\longrightarrow 0.05 \mathrm{~m} / \mathrm{s}$

Concentration component $1\left(\mathrm{~kg} / \mathrm{m}^{3}\right)$

(b)

FIGURE 20: Simulated flow patterns in the causeway area, driven by $10 \mathrm{~m} / \mathrm{s}$ constant east wind under the causeway with a single opening.

patterns in Figure 20. The surface flows, as expected, follow the driving wind direction. In the bottom layer, in order for the passing flow to have a strong effect on the local flows in the region on left side of the causeway, it should provide enough additional flow to compensate the surface flow which is pushed away (towards the west) by wind to reduce the surface slope (hydraulic pressure) built up by the wind, resulting in a reduction or even elimination of the bottom return flow (towards the east), which is not seen in Figure 20. If the main purpose of opening the causeway is to increase the flow activ- ities in the surrounding area to improve the water quality, it may not be as effective as expected because (1) under weaker winds, the generated exchange flow would not be capable of penetrating very far from the causeway opening, (2) not only would the exchange flow be too small to have a substantial influence on the local flow conditions under a weaker wind, but also the water qualities of the exchange flows from two sides in the shal-low water region near the causeway are very similar, (3) under stronger wind conditions, larger exchange flows can be induced, which also increases the surrounding 


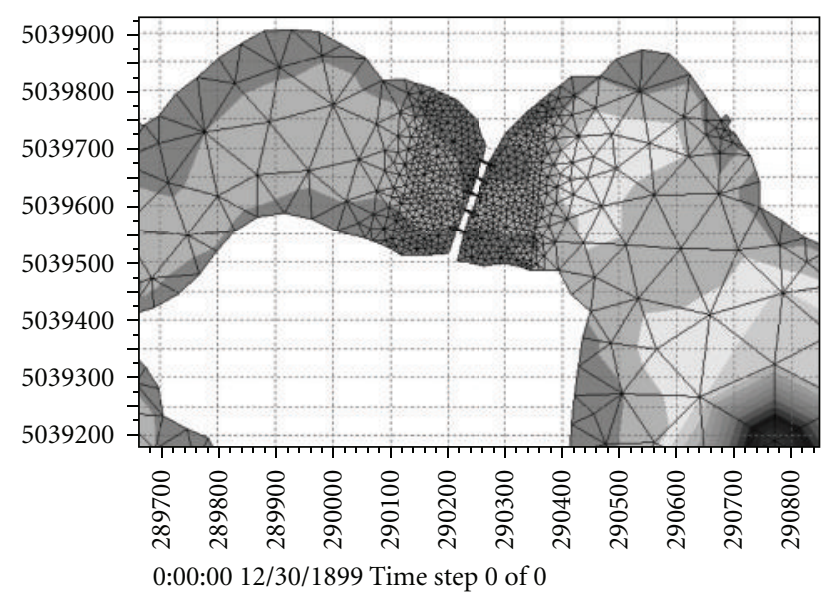

FIGURE 21: The model mesh used in the simulation for the causeway with a 5 culvert configuration.

ambient flows, reducing the importance of the induced exchange flows. It can be seen from the simulated flow patterns in Figure 20 that under the strong and persistent east wind, the better quality deep water can travel all the way to the shallow water region around the causeway through the bottom flows no matter whether the causeway has been opened up or not. This would improve the water quality in the shallow area. Under certain wind conditions such as the strong west wind, water quality in the deeper water area around the WTP intake will also possibly be degraded according to the similar bottom flow exchange mechanism. This may explain the past water quality issues which have occurred at the WTP intake location. The influences of windinduced two-layer flows on flow conditions and water quality would be much larger than those effects from the windinduced exchange flow as evidenced in Figure 20.

5.3. Causeway with Multiple Openings. A proposal to build four or five 2-3-meter diameter culverts crossing through the existing causeway was put forward by the local community and will be examined below. The potential advantage of this configuration compared to a single opening is that the exchange flows would be more evenly distributed along the causeway, which could reduce the possibility of creating dead zones induced by a single strong flow. As in the previous tests, both measured and $10 \mathrm{~m} / \mathrm{s}$ constant east winds were used in the simulations.

5.3.1. Under Natural Wind. The mesh used for the modeling of five culverts crossing through the causeway is displayed in Figure 21. A similar mesh used for the modeling of four culverts is not shown here. The culverts in the simulation are represented by 3 -meter-wide open channels, which may result in slightly larger simulated flow compared to that in a culvert because of wind effects on the water surface. Because the water depth in the vicinity of the causeway is in the range from $1 \mathrm{~m}$ to $3 \mathrm{~m}$, the cross-sectional area of an open channel should be similar to the cross-sectional area of a culvert with 2-3-meter diameters. As the width of the open channel is

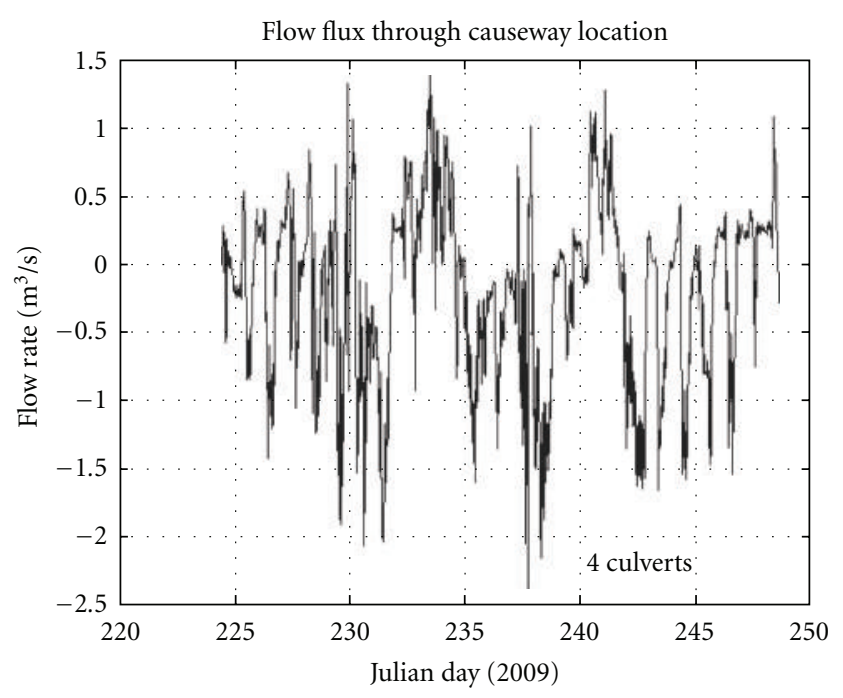

(a)

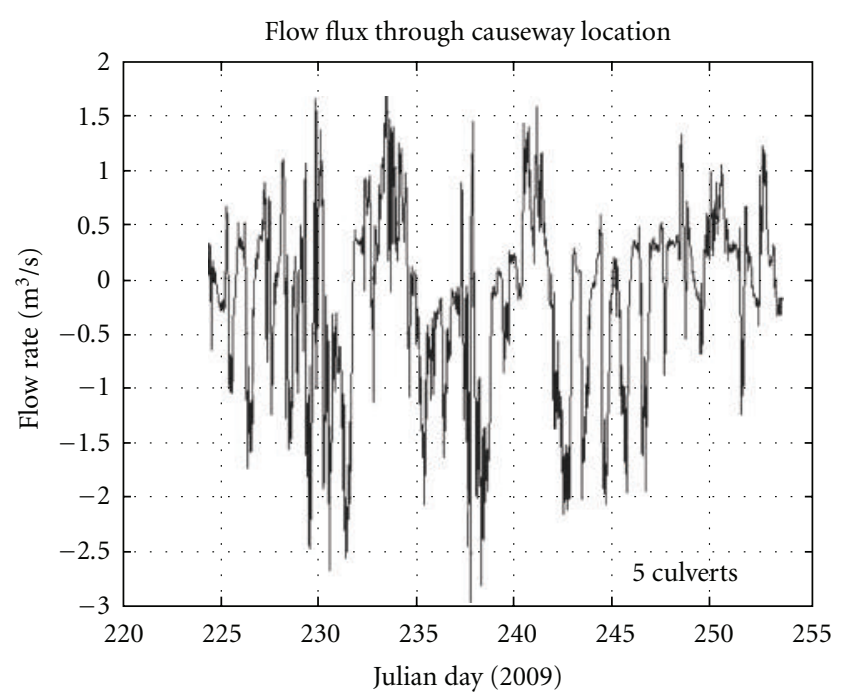

(b)

FIgure 22: The flow rates of the passing through the causeway, driven by natural wind and under the causeway configuration of 4 and 5 culverts.

relatively small compared to the dimension of the modeled domain, special care has to be taken to generate a modeling mesh in such way that there is a much higher mesh resolution in the vicinity of the causeway as shown in Figure 21, and the mesh resolution in the other parts of the modeling domain are similar to previous cases.

Figure 22 shows the exchange flow rates under the causeway configurations with four and five culverts. The maximum flow rate for four and five culvert configurations are 2.05 and $2.94 \mathrm{~m}^{3} / \mathrm{s}$, and the average flow rates are 0.51 and $0.62 \mathrm{~m}^{3} / \mathrm{s}$, respectively; but the average flow rate per unit is about the same under the two different structures. The simulated surface and bottom flow patterns for two configurations are displayed in Figure 23. As expected, the general flow patterns in both the surface and bottom layers 


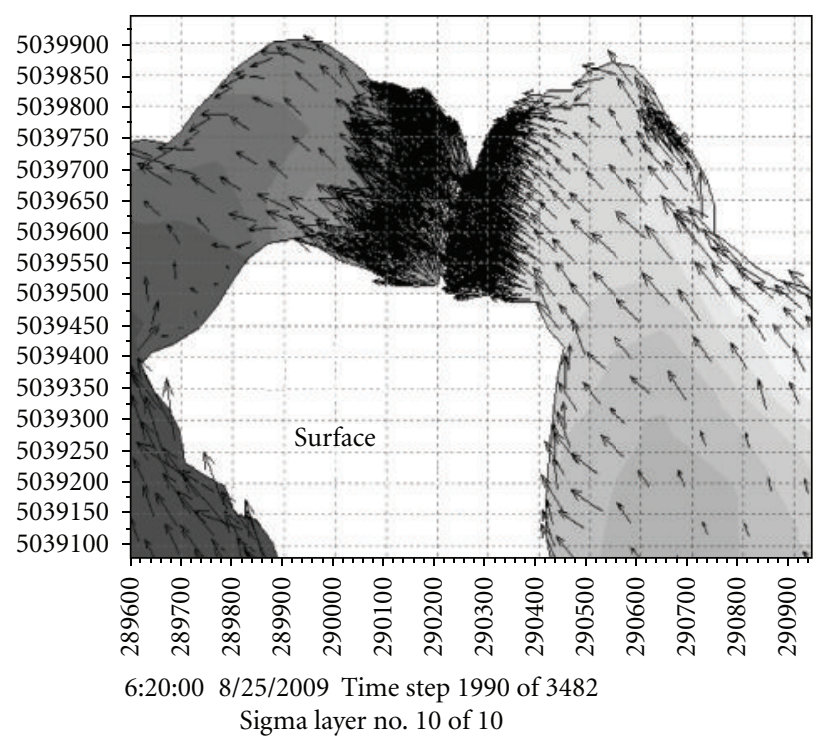

(a)

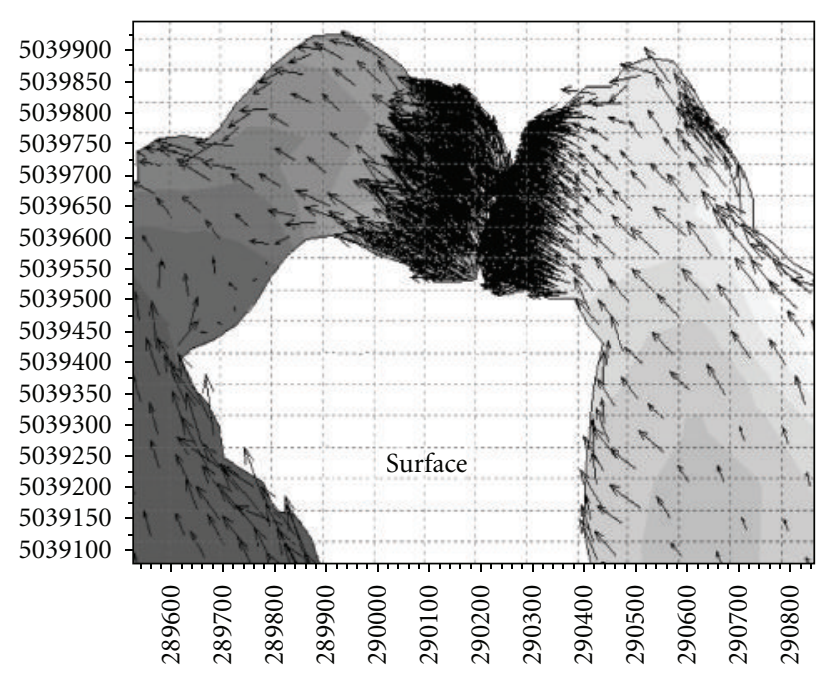

6:20:00 8/25/2009 Time step 1990 of 4188.

Sigma layer no. 10 of 10

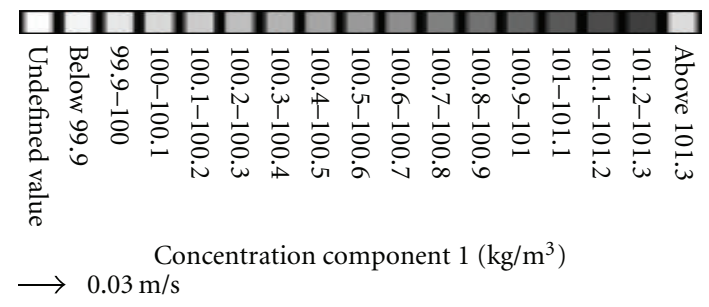

(c)

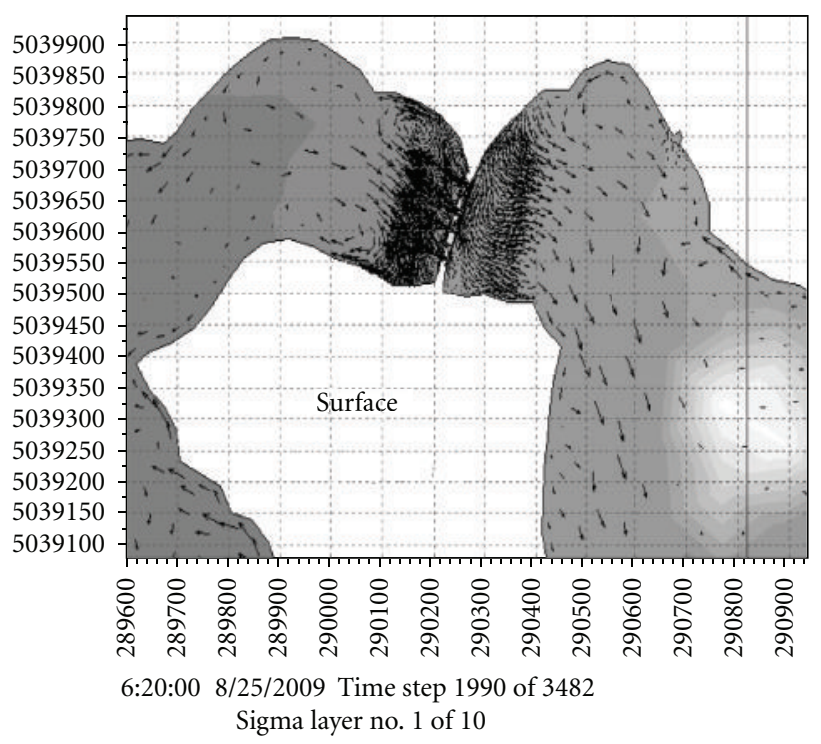

(b)

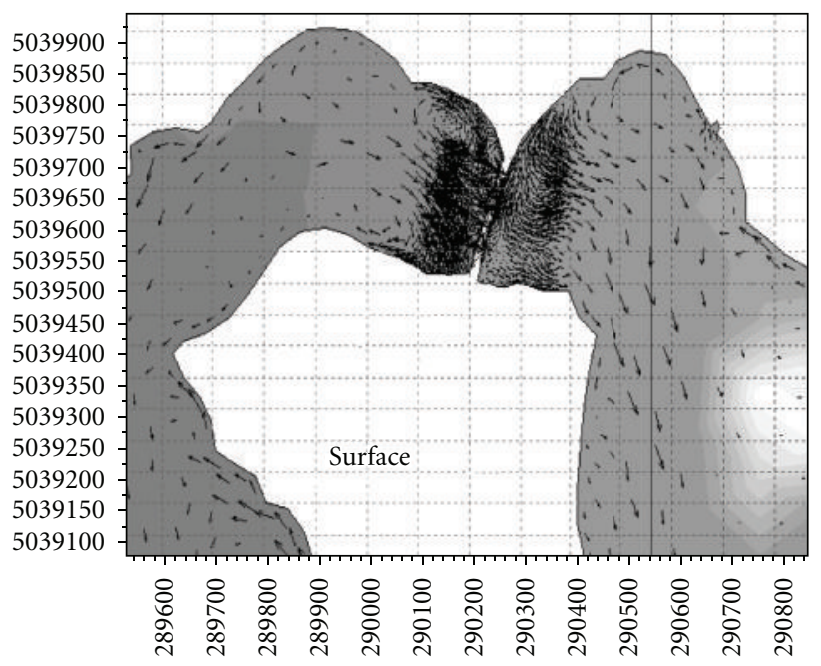

6:20:00 8/25/2009 Time step 1990 of 4188.

Sigma layer no. 1 of 10

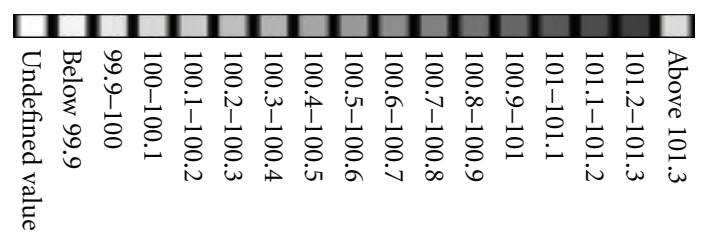

$\longrightarrow 0.03 \mathrm{~m} / \mathrm{s}$

Concentration component $1\left(\mathrm{~kg} / \mathrm{m}^{3}\right)$

(d)

Figure 23: The simulated surface and bottom flow patterns for the causeway with 4 and 5 culvert configurations.

are very similar. From the hydraulic point of view, there are no real differences between the two flow conditions; neither one would alter the present circulation pattern of the lake and would be not likely to induce any large flow circulation pattern around Mask Island.
5.3.2. Under Strong $10 \mathrm{~m} / \mathrm{s}$ Constant East Wind. Simulations with a strong constant east wind and different causeway configurations were also conducted and results are displayed in Figures 24 and 25. The simulated exchange flow rate with the 5 culvert insert configuration is about $22 \%$ larger than 


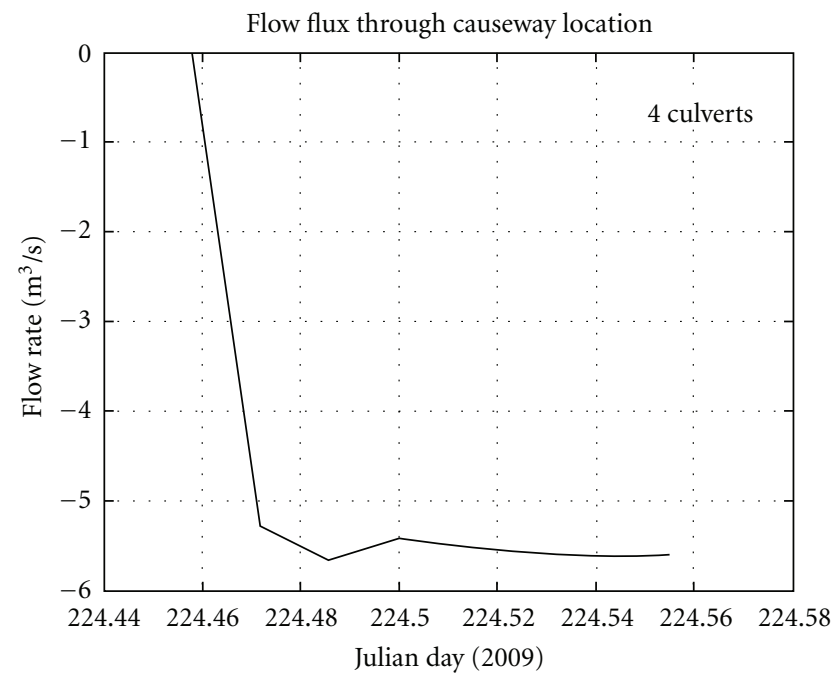

(a)

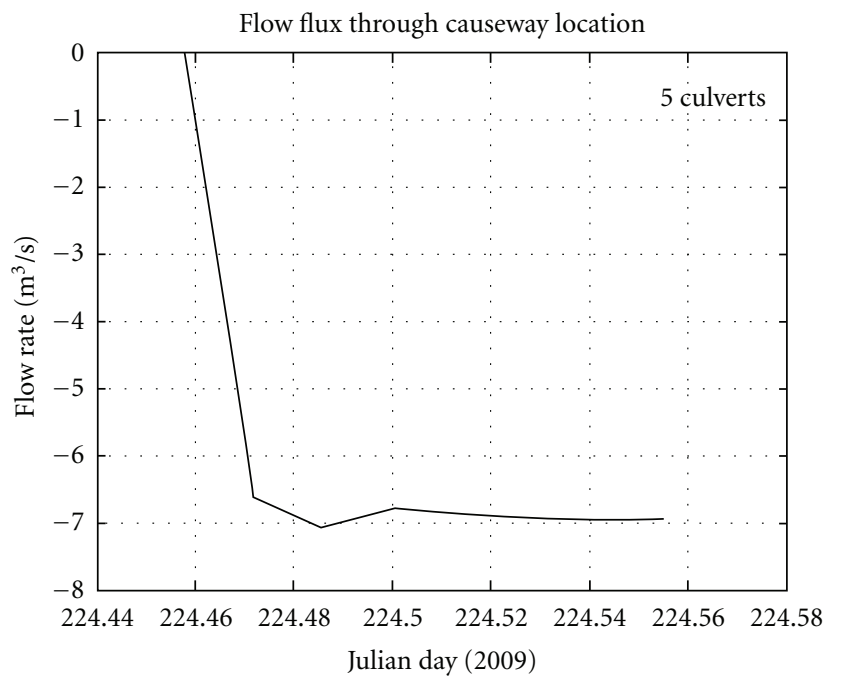

(b)

FIGURE 24: The exchange flow rates through the causeway under the 4 or 5 culvert configurations and natural wind.

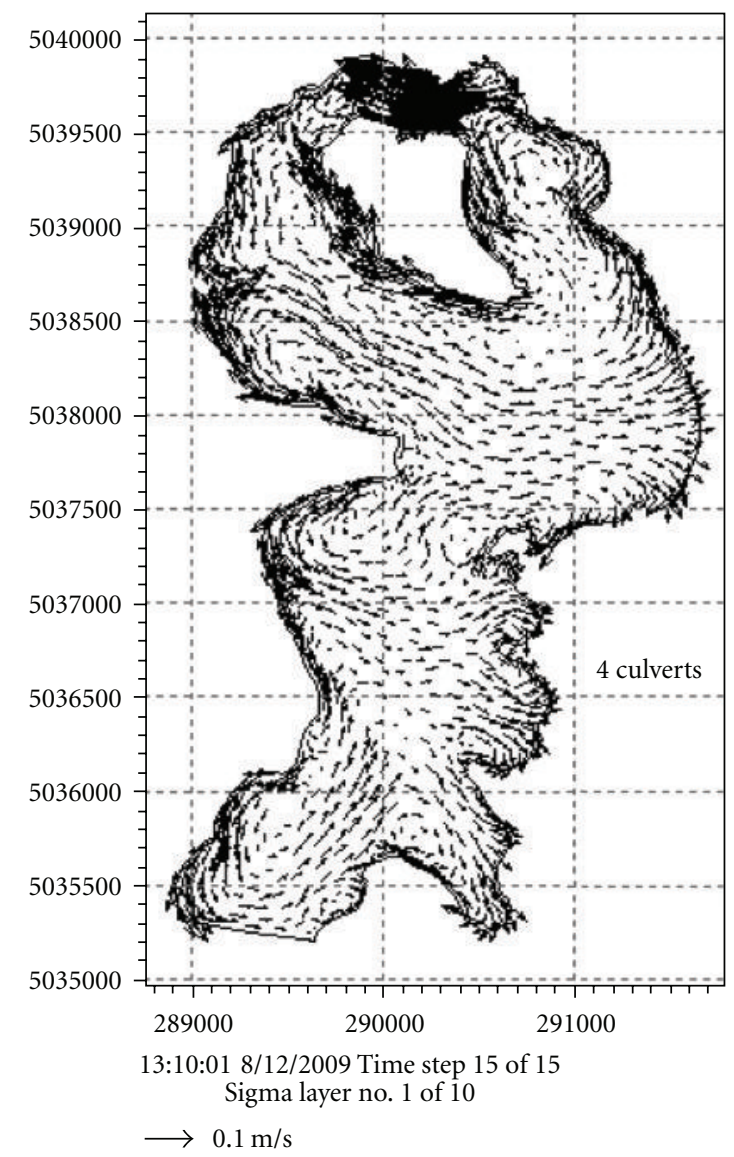

(a)

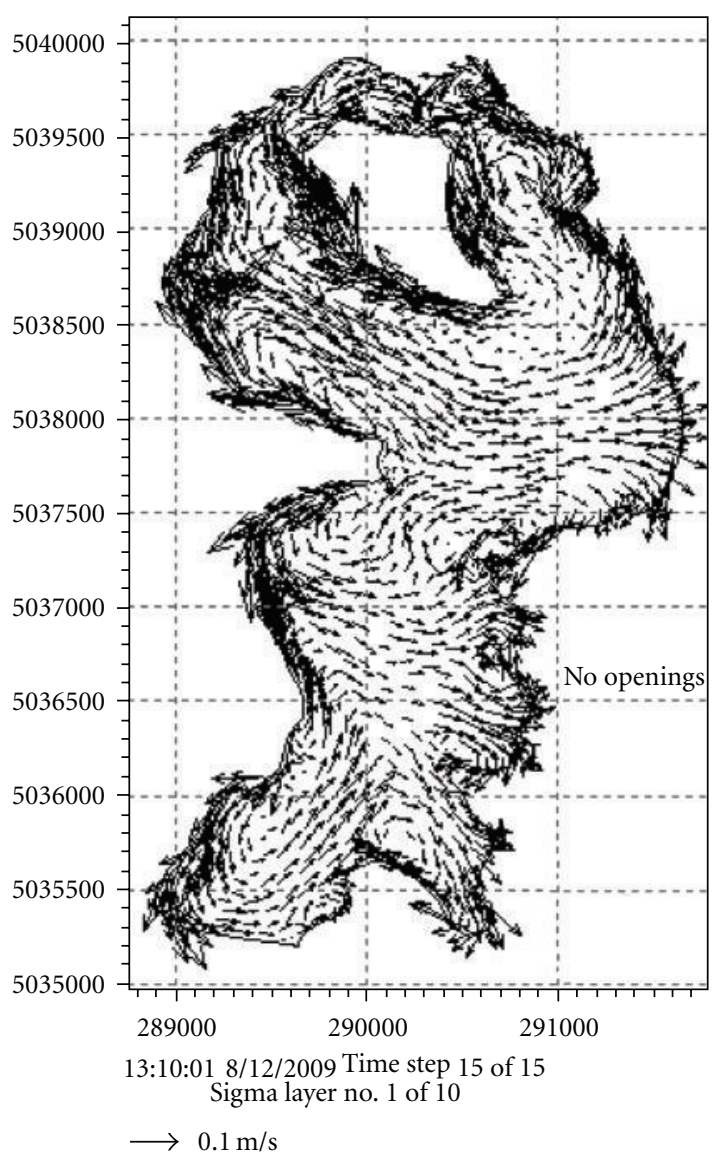

(b)

FIgURE 25: Comparison of the bottom flow patterns generated under $10 \mathrm{~m} / \mathrm{s}$ constant east wind with the 4 inserted culverts and a closed causeway. 


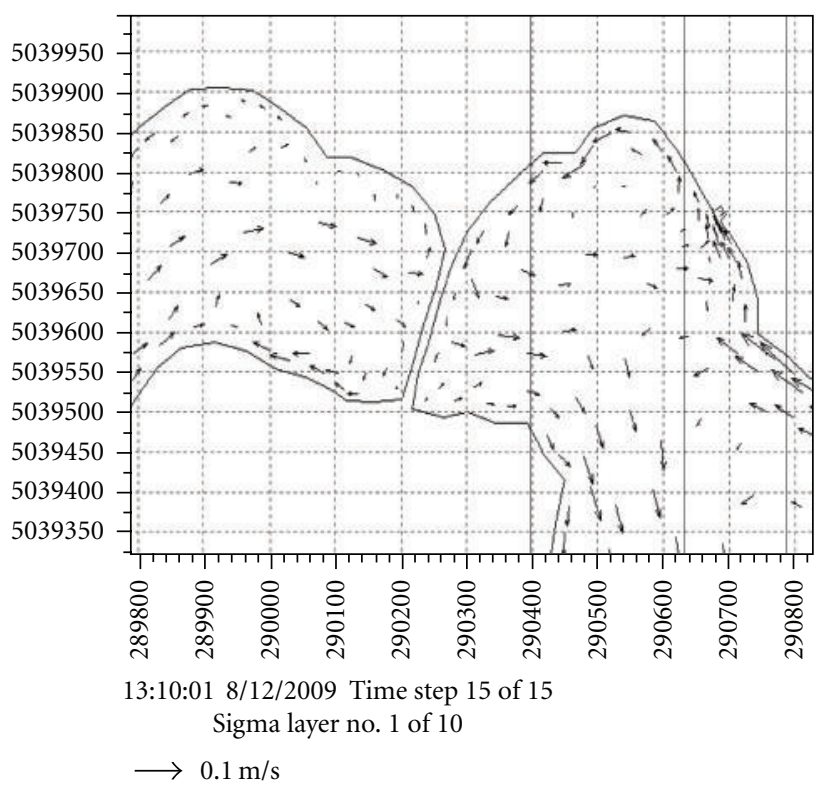

(a)

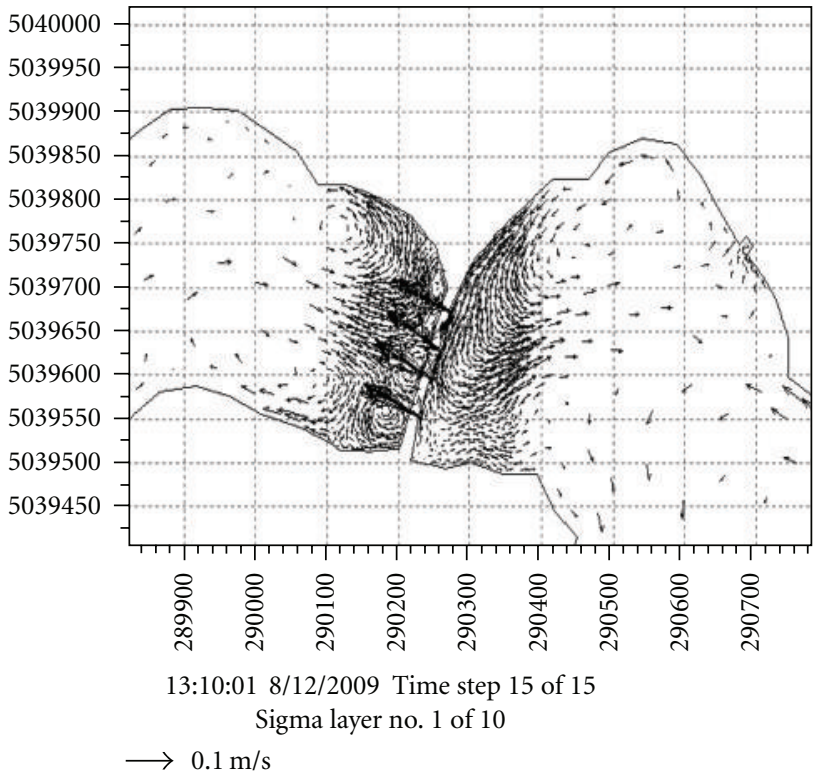

(b)

FIGURE 26: The bottom flow patterns under strong easterly wind with the closed and 4 inserted culvert causeway structures.

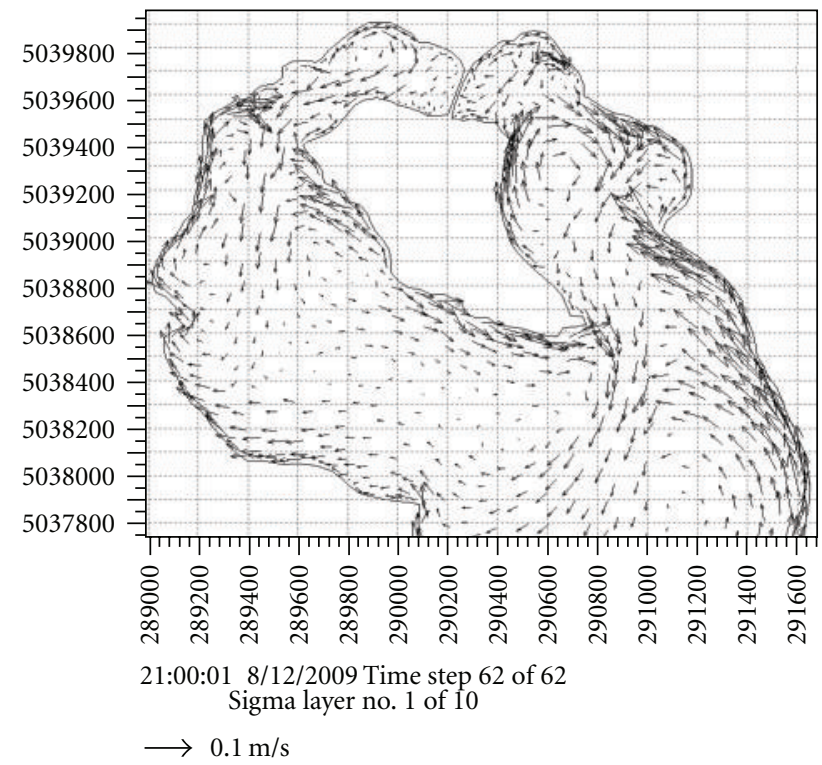

Figure 27: The bottom flow from the causeway shallow region to deep water and from the east side to west side of the island induced by $7 \mathrm{~m} / \mathrm{s}$ constant south-west wind.

that simulated under the 4 culvert insert configuration as shown in Figure 24. The nearly $6 \mathrm{~m}^{3} / \mathrm{s}$ exchange flow rate could possibly be large enough to have an influence on local hydraulic conditions, but, it was not expected to have a strong direct effect on the hydraulic conditions in most parts of the north basin, as indicated by the comparison of the bottom flow patterns with and without opening the causeway. One disadvantage when using culverts is that it does not generate flow without wind. However with wind, the flow in the vicinity of the causeway will be stimulated, but the exchange flow may not be significant enough for the purpose of improving the flow circulation. For instance, the east wind induced bottom flow patterns under the causeway structure with four inserted culverts may not have much effect on increasing the flow exchange compared to the same simulation with the closed causeway. Under weak winds the passing flow does not penetrate very far and with strong winds, the fast flows passing through the culverts generate small eddies on each side of the passing flows due to negative pressure as shown in Figure 26. The flows in these small 


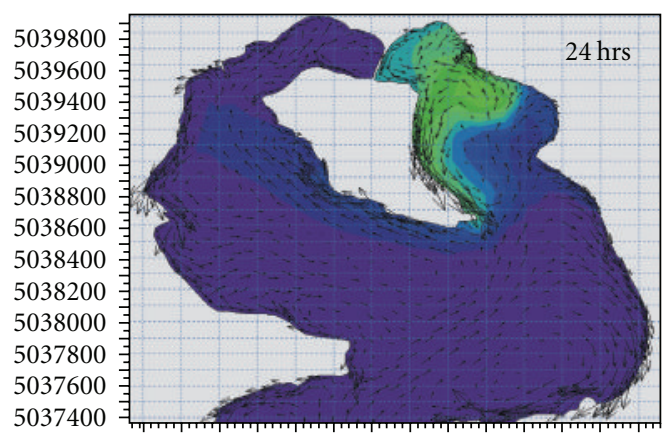

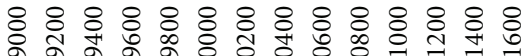
১ 10:40:00 8/13/2009 Time step 24 of 153 Sigma layer no. 5 of 10

(a)

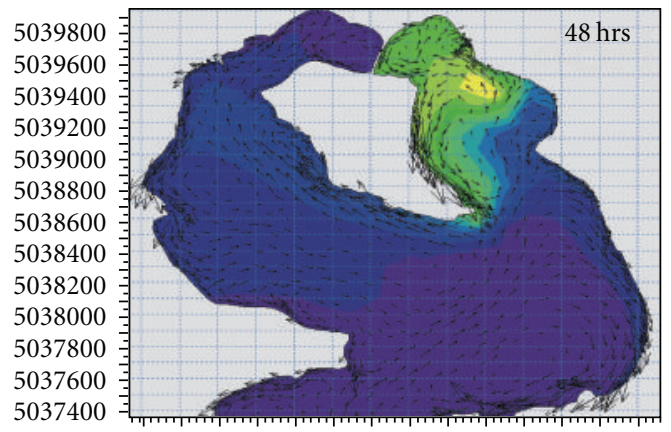

ஓ 융 \& ๙ 10:40:00 8/14/2009 Time step 48 of 153 Sigma layer no. 5 of 10

(c)

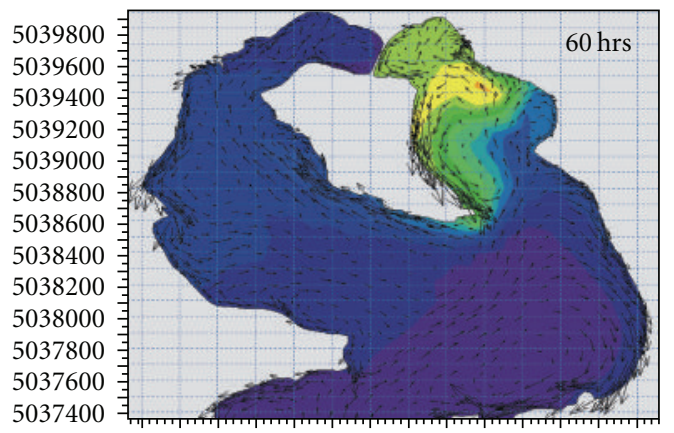

\& 융 \&

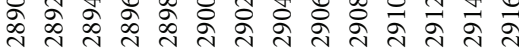

10:40:00 8/14/2009 Time step 60 of 153

Sigma layer no. 5 of 10

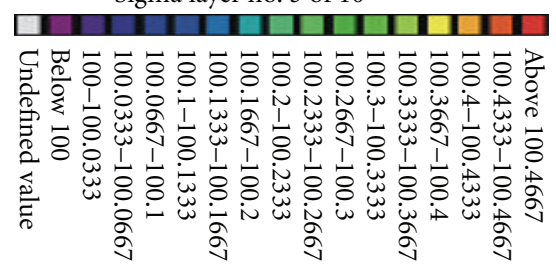

Concentration component $1\left(\mathrm{~kg} / \mathrm{m}^{3}\right)$ $\longrightarrow 0.05$

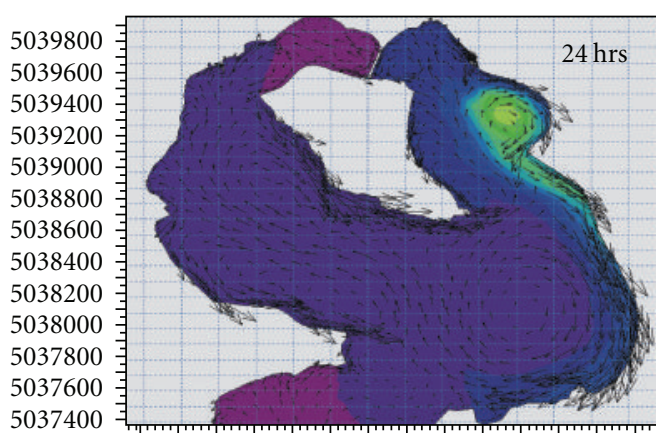

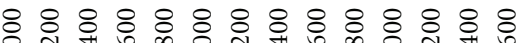
১ 10:40:00 8/13/2009 Time step 24 of 698 Sigma layer no. 5 of 10

(b)
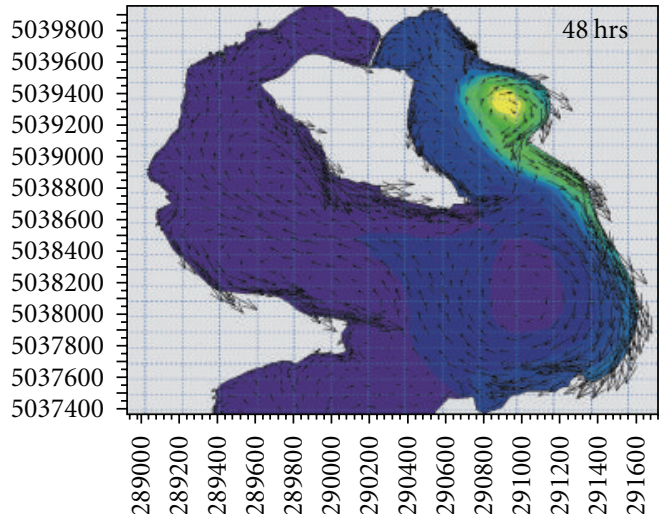

10:40:00 8/14/2009 Time step 48 of 698 Sigma layer no. 5 of 10

(d)

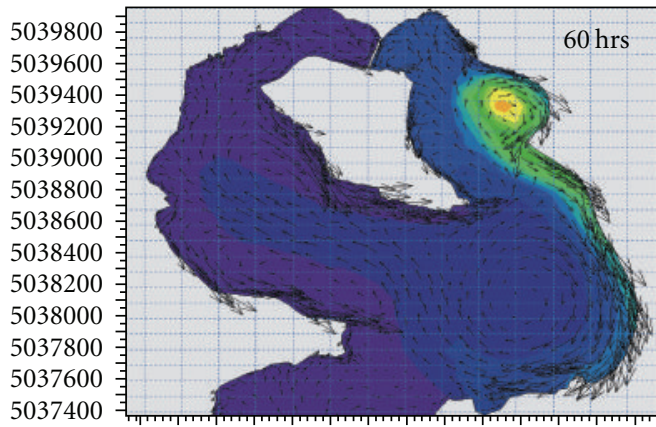

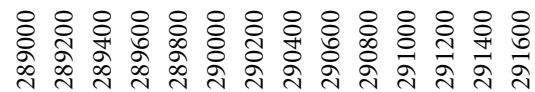

10:40:00 8/14/2009 Time step 60 of 698

Sigma layer no. 5 of 10

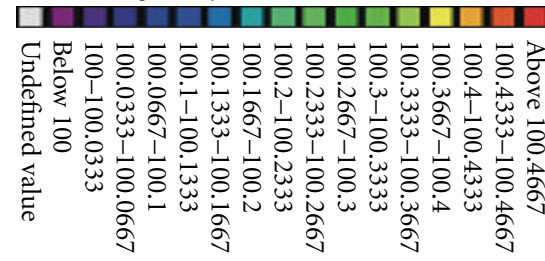

Concentration component $1\left(\mathrm{~kg} / \mathrm{m}^{3}\right)$ 0.05

(e) 


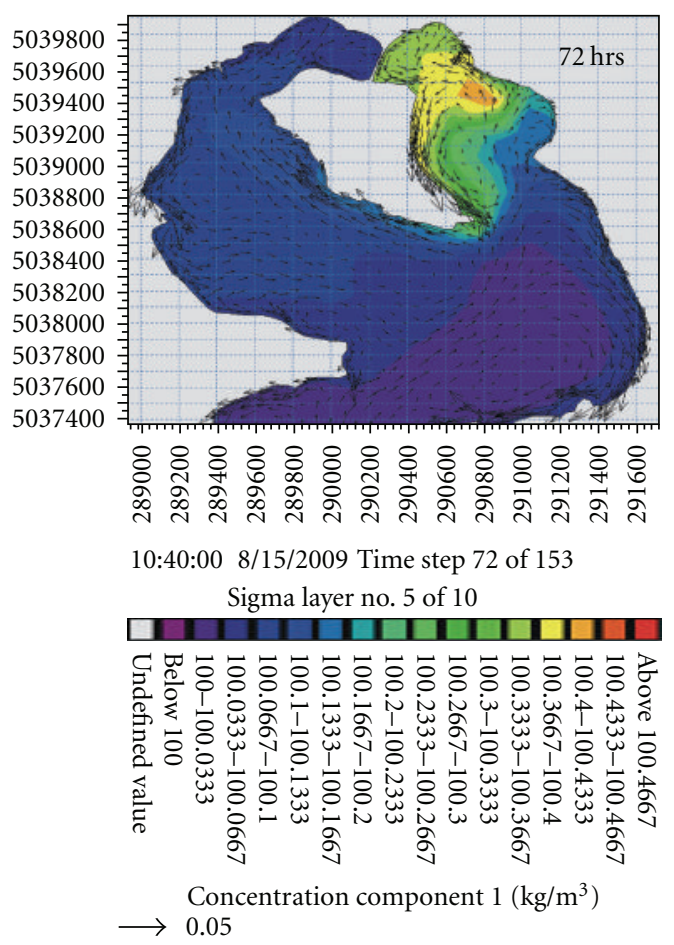

(g)

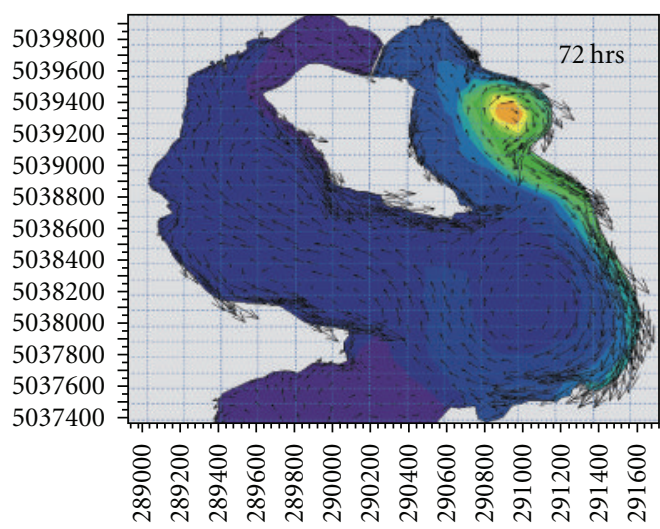

10:40:00 8/15/2009 Time step 72 of 698

Sigma layer no. 5 of 10

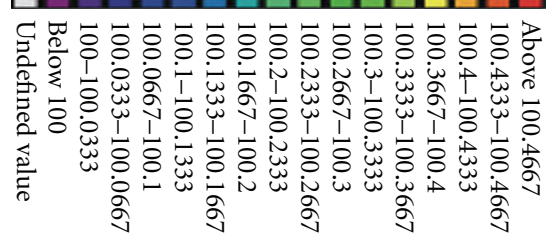

Concentration component $1\left(\mathrm{~kg} / \mathrm{m}^{3}\right)$ $\longrightarrow 0.05$

(h)

FIGURE 28: The simulated time series of the transport of the STP discharge plumes at the middle water depth in the north basin after travelling for 24, 48, 60, and 72 hours under north-east (left side panels) and north-west (right side panels) winds of $10 \mathrm{~m} / \mathrm{s}$.

eddies tend to circulate locally, which may reduce the chance of exchange with the higher-quality deep bottom water brought by the flows passing through culverts.

5.4. Water Quality Issues at the WTP Intake. Due to the lack of field data on water quality, the main purpose of this section is to provide some qualitative information based on the numerical simulations about possible explanations for water quality variation under the influence of different hydraulic conditions.

It has been shown from previous modeling results that wind-induced flows most likely display a two-layer flow pat-tern. Under the east wind, the deep water from the WTP intake region would be brought up to the shallow water region around the causeway area through the bottom, against the direction of the wind flows. Based on the same principle, if the wind was from the south-west, the bottom water in the shallow water region could be pushed down to the WTP intake area by the hydraulic pressure due to the raised water surface level at the vicinity of the causeway, as indicated by the flow patterns in Figure 27. The results in Figure 27 are from the simulation driven by a constant south-west (210 degree) wind of $7 \mathrm{~m} / \mathrm{s}$ with a closed causeway in place. Actually, additional simulations show that any winds from the direction range from 180 (south) to 270 (west) degrees would produce similar flow patterns as shown in Figure 27.

The flows in the vicinity of the STP discharge can also be transported into the area of the WTP intake under favorable wind conditions. Figure 28 shows the simulated time series of the transport of the STP discharge plumes at the middle water depth in the north basin. The plume patterns displayed in Figure 28 indicate the progressive results of the plumes after being discharged and travelling for $24,48,60$, and 72 hours under north-east (on left side panels) and northwest (on right side panels) constant winds of $10 \mathrm{~m} / \mathrm{s}$. The transport model is integrated with the hydrodynamic model, and the plume transport was updated at each time step after the flow velocity field was calculated from the hydrodynamic model. In the simulation, the backgroundspecific conductance value of $100 \mu \mathrm{S} / \mathrm{cm}$ was specified for the whole lake except at the location of the STP discharge where a much higher value $(2000 \mu \mathrm{S} / \mathrm{cm})$ was assigned. The diffusivity constant used in the simulation is $0.01 \mathrm{~m}^{2} / \mathrm{s}$; the simulated results were found to be insensitive to the values of the applied diffusivity under the simulated strong wind scenario because the plume transport caused by the strong currents (advection) is much larger than those induced by the plume concentration gradient (diffusion). Obviously, the travel time of the plumes reaching the other side of the island largely depends on the wind-induced flow patterns. Under the north-east wind the plumes reach the WTP intake area faster than the plumes driven by the north-west wind because under the winds from two different directions, the plumes travel along different sides of the shoreline to reach the other side of the island. After about 60 hours (2.5 days), the plume fronts (represented by the blue color) could arrive in the vicinity of the WTP intake under either wind direction, resulting in potential effects upon the local 
water quality. Because the average duration of the prevailing north wind is about 2-4 days as mentioned before, the scenario of the STP discharge plumes being transported to the other side of the island is highly likely under favorable wind conditions. However, after travelling for a certain time, the more highly concentrated plumes (as indicated by green and other colours) seem to be stalled, possibly due to the spreading effect. Therefore, unless a very strong north-east or north-west wind blows constantly for a long period, the STP discharge plumes may only have a limited influence on the water quality in the WTP intake area.

\section{Conclusions}

The wind is the main force which determines the flow conditions in the lake studied and drives the flow-passing through the proposed inserted culverts, instead of the static hydraulic pressure (as it is in the case of a river). The functionality of the proposed inserted culverts or other forms of open structures is closely associated with the wind conditions. Based on the numerical modeling results of the different examined scenarios, the following conclusions may be obtained.

(1) Under low wind conditions, the induction of strong flow exchanges between the deep and shallow water areas is not expected; the exchange flows generated by alternating direction may not extend very far from the causeway. The exchange flows may have very limited influences on the local water quality because the water quality on both sides of the causeway is similar and the flows from one side do not necessarily provide real benefits to the other side, except for stimulating some weak flow activities in the local region.

(2) Under a constant strong wind, the induced exchange flow would provide a flow source for the down-wind side of the causeway to compensate for the loss of surface water driven away from the causeway by the wind, which would lessen the need for bottom opposite to wind flows from deeper water. This results in reducing the flow exchange between deep water and shallow water. From this point of view, modifying the causeway with a few openings may not be an effective way to improve the local water quality.

(3) Under the strong constant east wind and removal of the entire causeway, a large bottom circulation around Mask Island could be formed, which would provide a chance to bring better quality deep water into the shallow water region around the causeway.

(4) Because the average duration of the prevailing north wind is about 2-4 days, it is realistic to expect that some of STP discharge plumes will be transported to the other side of the island. However, the simulation results indicate that after travelling for a certain time, the more highly concentrated plumes (as indicated by green and other colours) become stalled, possibly due to the spreading/dissipation effect. Therefore, unless a very strong north-east or north-west wind blows constantly for a long period, the STP discharge plumes may only have a limited influence on the water quality in the WTP intake area for most of time.

In summary, under a strong wind, the flow in the shallow area of the vicinity of the causeway will exchange with deeper bottom flow through the wind induced two layer flow movements whether or not the causeway is opened. A large island circulation is unlikely to be generated, even with a partial opening of the causeway because the induced exchange flows are too weak to affect the hydraulic conditions in the deeper water region of the lake and the variation of the natural wind is also not favourable for the formation of large circulation patterns around the island. If the entire causeway is removed, it still does not guarantee generation of a large circulation pattern surrounding the island under natural winds because the gradients of the wind-induced hydraulic pressure on two opposite sides of the island are similar, resulting in many small-scale circulation patterns, instead of a large circulation pattern being generated. This is typical of wind induced flow patterns in a small close basin.

\section{Acknowledgments}

The present paper was financially supported by Cambium Environmental Inc. Thanks are due to the field data collection by NWRI Technical Operations Services and Brian Trapp; without their assistance, this paper would not have been completed under such a tight time frame.

\section{References}

[1] J. R. Bennett, "A three-dimensional model of Lake Ontario's summer circulation, part I: comparison with observations," Journal of Physical Oceanography, vol. 7, pp. 591-601, 1977.

[2] E. Hollan and T. J. Simons, "Wind-induced changes of temperature and currents in Lake Constance," Meteorology and Atmospheric Physics, vol. 27, pp. 333-373, 1978.

[3] T. J. Simons, Circulation Models of Lakes and Inland Seas, Canadian Bulletin of Fisheries and Aquatic Sciences, Bulletin 203, Ottawa, Canada, 1980.

[4] N. R. B. Olsen and D. K. Lysne, "Numerical modelling of circulation in lake sperillen, norway," Nordic Hydrology, vol. 31, no. 1, pp. 57-72, 2000.

[5] J. Zhen-Gang, Hydrodynamics and Water Quality: Modeling Rivers, Lakes, and Estuaries, John Wiley \& Sons, Hoboken, NJ, USA, 2008.

[6] Y. R. Rao, C. H. Marvin, and J. Zhao, "Application of a numerical model for circulation, temperature and pollutant distribution in Hamilton Harbour," Journal of Great Lakes Research, vol. 35, no. 1, pp. 61-73, 2009.

[7] C. He, C. Curtis, R. Yerubandi, and C. Marvin, "Randle reef hydrodynamic numerical modeling study," NWRI Contribution AEMRB-TN08-002, 2008.

[8] E. B. Rasmussen, A. Driscoll, T. S. Wu, and R. Copp, "Nested hydrodynamic modeling using the MIKE 3 model," in Proceedings of the International Conference on Estuarine and Coastal Modeling, pp. 949-968, Monterey, Calif, USA, 2004.

[9] Q. Y. Zhang, "Comparison of two three-dimensional hydrodynamic modeling systems for coastal tidal motion," Ocean Engineering, vol. 33, no. 2, pp. 137-151, 2006.

[10] C. Chevalier, I. Sehested Hansen, E. K. Rasmussen, and H. J. Vested, "Modelling thermal plumes-Odense fjord example," Houille Blanche, no. 5, pp. 29-36, 2007.

[11] G. Lessin and U. Raudsepp, "Modelling the spatial distribution of phytoplankton and inorganic nitrogen in Narva Bay, southeastern Gulf of Finland, in the biologically active period," Ecological Modelling, vol. 201, no. 3-4, pp. 348-358, 2007. 

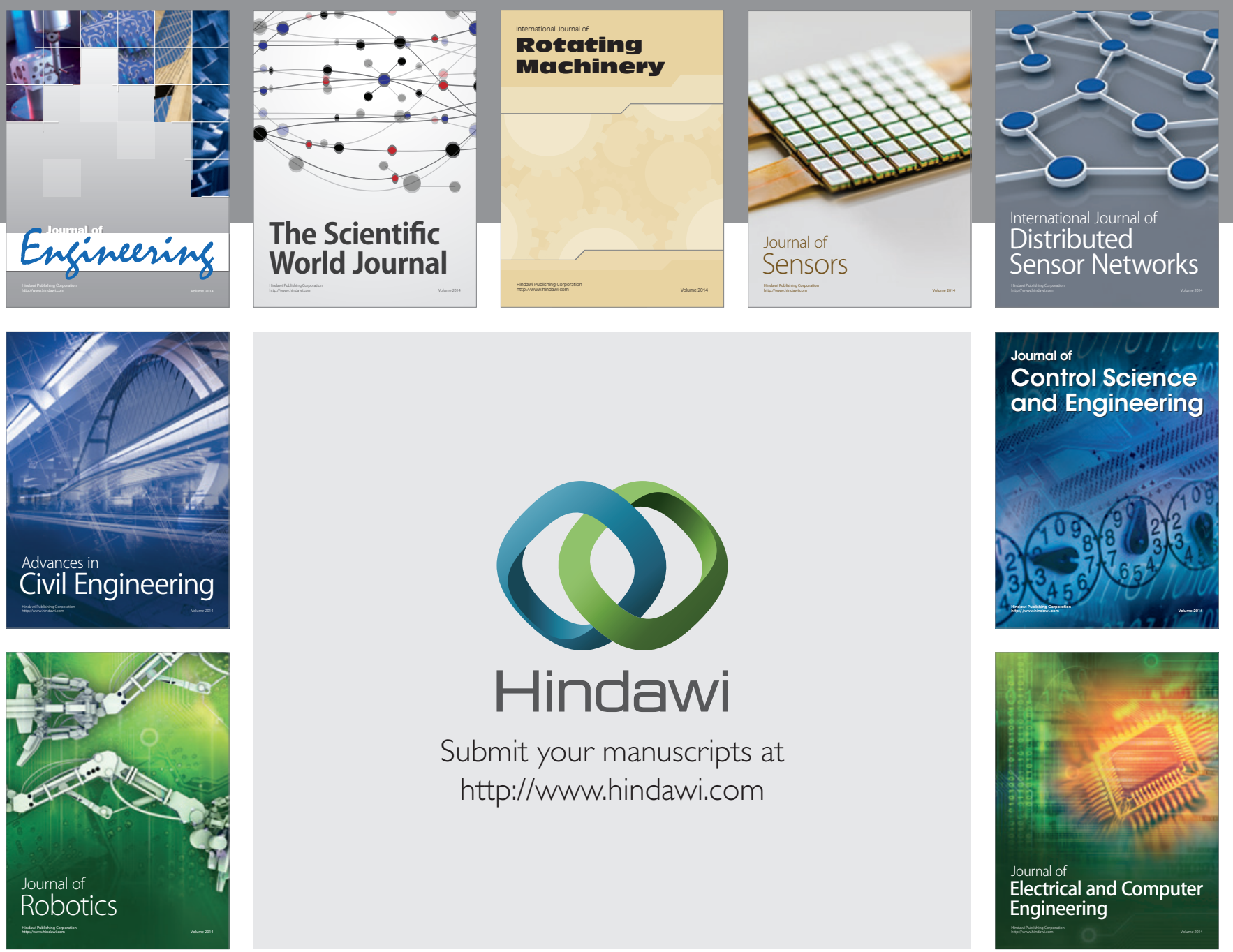

Submit your manuscripts at

http://www.hindawi.com
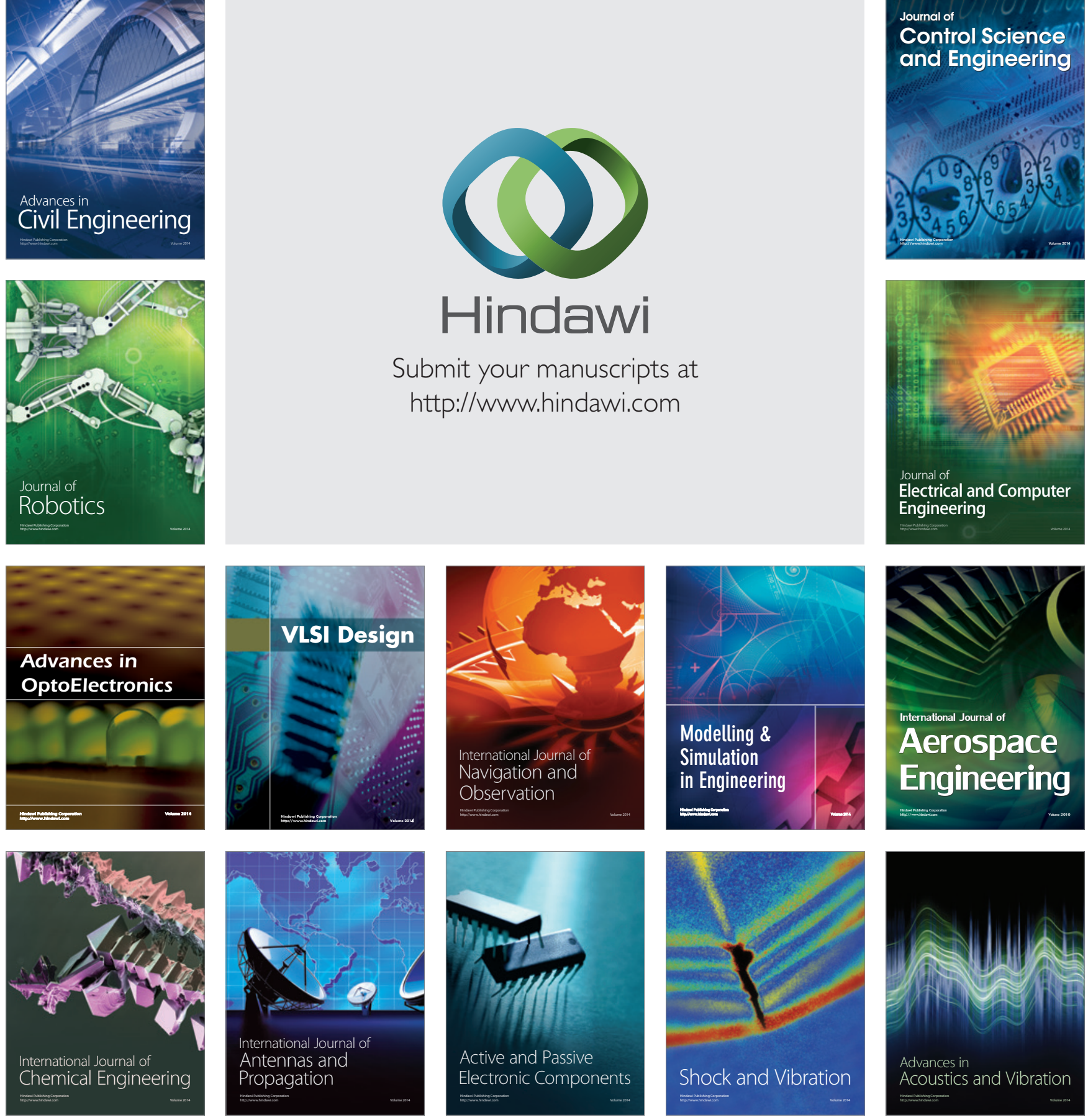